Vico Triguero, L., Molina González, F., Cámara Serrano, J. A. y Gámiz Caro, J. (2018):

"Estudio tecno-tipológico de las cerámicas del Cobre Reciente de los Castillejos

(Montefrío, Granada)", Spal 27.2: 29-53.

DOI: http://dx.doi.org/10.12795/spal.2018i27.15

\title{
ESTUDIO TECNO-TIPOLÓGICO DE LAS CERÁMICAS DEL COBRE RECIENTE DE LOS CASTILLEJOS (MONTEFRÍO, GRANADA)
}

\author{
TECNO-TYPOLOGICAL STUDY OF RECENT COPPER CERAMICS \\ OF LOS CASTILLEJOS (MONTEFRÍO, GRANADA)
}

\author{
LAURA VICO TRIGUERO \\ Departamento de Prehistoria y Arqueología de la Universidad de Granada. Campus de Cartuja s/n, 18071, Granada. \\ Correo-e: Ivico@ugr.es ORCID: https://orcid.org/0000-0002-9511-5577 \\ FERNANDO MOLINA GONZÁLEZ \\ Departamento de Prehistoria y Arqueología de la Universidad de Granada. Campus de Cartuja s/n, 18071, Granada. \\ Correo-e: molinag@ugr.es ORCID: https://orcid.org/0000-0002-9189-4198 \\ JUAN ANTONIO CÁMARA SERRANO \\ Departamento de Prehistoria y Arqueología de la Universidad de Granada. Campus de Cartuja s/n, 18071, Granada. \\ Correo-e: jacamara@ugr.es ORCID: https://orcid.org/0000-0003-4007-0639 \\ JESÚS GÁMIZ CARO \\ Departamento de Prehistoria y Arqueología de la Universidad de Granada. Campus de Cartuja s/n, 18071, Granada. \\ Correo-e: jegamiz@ugr.es ORCID: https://orcid.org/0000-0002-1345-7910
}

\begin{abstract}
Resumen: En este trabajo se presentan los resultados obtenidos mediante la aplicación de difracción de rayos X y estereomicroscopía a las cerámicas halladas en las campañas de excavación realizadas entre los años 1991 y 1994 en los niveles del Cobre Reciente (2600-2000 cal. A.C) de Los Castillejos (Montefrío, Granada). Estas técnicas analíticas han permitido estudiar la producción cerámica de este yacimiento en el último momento de la Edad del Cobre, basándonos en la caracterización de sus pastas cerámicas, así como en la tipología de sus formas. A partir de nuestro estudio hemos podido determinar que las producciones son de carácter local, realizadas en su mayor parte con materias primas procedentes del entorno de Los Castillejos, cuyo proceso de manufactura denota cierta pericia por parte de los productores cerámicos, pese a que no se puede hablar de una sistematización de la fabricación cerámica debido a la escasa relación entre forma-tecnología.
\end{abstract}

Palabras clave: Cobre Reciente; Los Castillejos; cerámica; tecnología; mineralogía; producción.

\begin{abstract}
In this research work we present the results obtained through the application of X-ray diffraction and stereomicroscopy to the pottery found in the excavation campaigns carried out between 1991 and 1994 at the levels of Late Copper Age of Los Castillejos (Montefrío, Granada). These analytical techniques have allowed us to study the ceramic production of this deposit at the last moment of the Copper Age, based on the characterization of its ceramic pastes, as well as the typology of its forms. From our study we have been able to determine that the productions are of local character, made mostly with raw materials from the environment of Los Castillejos, whose manufacturing process denotes some skill by the craftsman, although it's hard to confirm a systematization of ceramic manufacturing due to the poor relation between form-technology.
\end{abstract}

Keywords: Late Cooper Age; Los Castillejos; pottery; technology; mineralogy; process. 


\section{INTRODUCCIÓN Y OBJETIVOS}

Aunque el estudio arqueométrico de las cerámicas arqueológicas para una mejor aproximación a las técnicas de realización de los recipientes, las materias primas empleadas y la funcionalidad a la que irían dedicados, tiene una amplia tradición (Shepard 1954, Orton 1997, Gibson y Woods 1997, Cuomo di Caprio 2007, Echellier 1984, Rice 1987), incluso en el caso de la península ibérica (Navarrete et al. 1991, Capel 1979, 1985, 2001, Capel y Delgado 1978) su incremento en los últimos años (García Roselló y Trías 2006, Albero 2011, Cubas 2013, Cubas y Ontañón 2009, Cubas et al. 2012, Gámiz et al. 2013b, Odriozola y Hurtado 2007, Odriozola 2012, Dias et al. 2017) debe ser atribuido a varios motivos. Por un lado, a la constatación definitiva de las posibilidades del método, gracias también al desarrollo de las analíticas y a la mejora de los protocolos. Por otro lado, a un énfasis general dentro de la disciplina arqueológica hacia estudios más integrales sobre la totalidad de la cultura material, aun con los costes adicionales que ello implica. Esto permite conocer con mayor profundidad el comportamiento de las sociedades pasadas. En este contexto, esta investigación pretende dar respuesta a una serie de cuestiones relacionadas con la producción cerámica y la procedencia de los recipientes a través de una serie de métodos provenientes de las Ciencias de la Tierra, utilizando para ello técnicas analíticas como la estereomicroscopía y la difracción de rayos X (DRX) para el estudio de las pastas cerámicas y su composición mineralógica.

El material arqueológico del yacimiento de Los Castillejos (Montefrío, Granada) está siendo sometido a esta estrategia de estudio integral (Riquelme 1998, Sánchez 1999, Pau 2016, Martínez 2016). En lo que respecta a la cerámica, se requería resolver las diferentes cuestiones mencionadas, especialmente en los niveles de transición entre los diferentes periodos que caracterizan su amplísima secuencia (Corral 2007), centrándose este estudio concretamente en el Cobre Reciente. Hasta el presente trabajo, sólo se había realizado un análisis tipológico de materiales de la misma cronología extraídos en las campañas efectuadas entre los años 1971 y 1974, en concreto del Corte 1 (Arribas y Molina 1979a, 1979b). Del mismo modo, con la realización de este trabajo, la tipología se ha visto ampliada tras el estudio de los materiales procedentes de las campañas de 1991-1994 (Vico 2016).

Por todo lo anterior, entre los objetivos de este trabajo está la aportación de nueva información acerca de la producción cerámica de este yacimiento y el grado de estandarización durante los momentos más tardíos de la Edad del Cobre.

Asimismo, la realización de estudios con el mismo protocolo metodológico sobre otras fases de la secuencia de Los Castillejos permite situar en una perspectiva evolutiva nuestros resultados e incluso con la escasez de estudios de este tipo para el Cobre Reciente, la precisa seriación de los materiales de Los Castillejos permite un análisis comparativo entre las producciones cerámicas acaecidas durante el período cultural aquí estudiado en otros yacimientos, con el fin de poder analizar las actividades socioeconómicas de este momento.

\section{LOCALIZACIÓN DE LOS CASTILLEJOS}

La zona de estudio se emplaza en el municipio de Montefrío, situado en los montes occidentales de la provincia de Granada, entre la sierra de Loja al oeste y el pasillo de Pozo Alcón al este, formando el borde septentrional de la depresión de Granada (Onieva 1977, Arribas y Molina 1977, 1979a, Cámara et al. 2016). Esta amplia comarca está formada por una serie de montañas y valles que forman parte de las cordilleras Subbéticas (Moreira 2003).

El enclave arqueológico de Los Castillejos se sitúa concretamente en la formación cárstica conocida como "Peñas de los Gitanos" (fig. 1.), una meseta elevada (1034 m s.n.m. de altura máxima) que se extiende al noroeste de la sierra de Parapanda y que se encuentra fraccionada en múltiples unidades (más elevadas y más deprimidas) como resultado de fenómenos cársticos de fisura y deslizamiento de bloques (Moreira 2003). El ambiente en el que se ubica el yacimiento arqueológico se caracteriza por una serie de "maciños", que forman un relieve suave debido a su naturaleza margosa y margocaliza que lo hace fácilmente erosionable, lo que, junto con el deslizamiento que ha provocado la caída de bloques y derrumbes originados por el hundimiento de pequeñas simas, ha dado lugar a un relieve cárstico constituido por pasillos encajados entre zonas más elevadas, además de grandes bloques dispersos y abrigos y cuevas creados ya sea directamente por la actividad del agua o por la superposición de bloques caídos como resultado de la erosión de esta (Onieva 1977, Ruiz Bustos 1979, Cámara et al. 2016).

El territorio está recorrido por dos cursos hidrográficos, por un lado el Barranco del Castellón, situado al oeste del yacimiento y, por otro, el arroyo de los Molinos, que discurre flanqueando el yacimiento por el este 


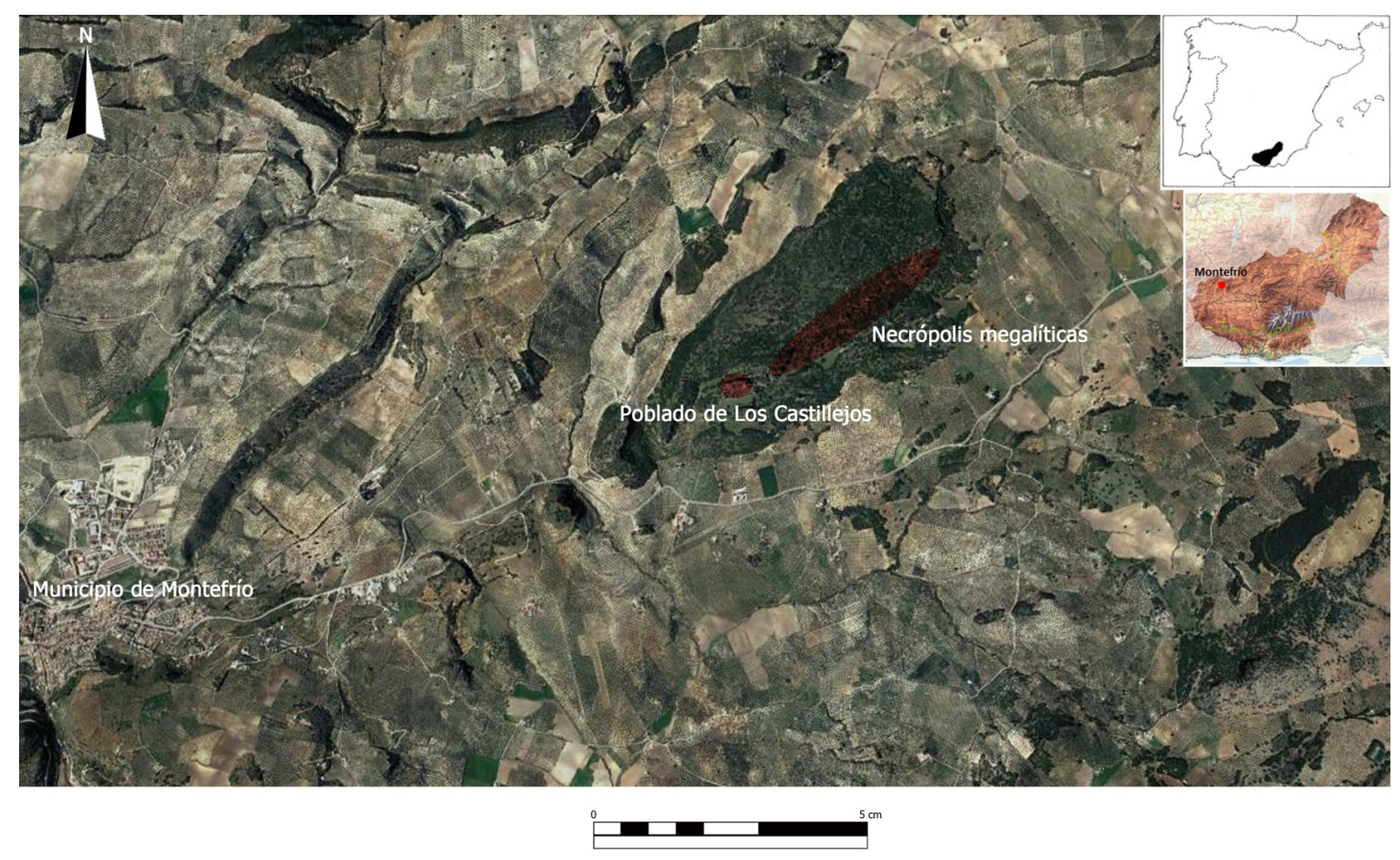

Figura 1. Localización de Los Castillejos en las Peñas de los Gitanos.

y sureste, atravesando el valle fértil que se sitúa entre el relieve de Las Peñas y la sierra de Parapanda, para desembocar más adelante en el río Genil.

Esta meseta tuvo su génesis a partir de la orogenia alpina, como el resto de las Béticas, incluyendo, por tanto, materiales fundamentalmente sedimentarios procedentes de contextos marinos (Onieva 1977), con abundantes fósiles, procedentes de formaciones miocénicas IGME (1985-87).

\section{LAS CERÁMICAS OBJETO DE ESTUDIO}

Los trabajos arqueológicos se han focalizado especialmente en el extremo oriental del poblado de Los Castillejos, donde se ha documentado una amplia secuencia de ocupación prehistórica, que comprende desde el Neolítico hasta la Edad del Bronce Inicial (Arribas y Molina 1979b, Afonso et al. 1996, Ramos et al. 1997, Cámara et al. 2005, 2016). Como hemos dicho, el presente trabajo se ocupa de los materiales del Cobre Reciente recuperados en las últimas campañas de excavación (Ramos et al. 1997, Cámara et al. 2016) realizadas entre 1991 y 1994.
Se ha seleccionado un total de 222 fragmentos cerámicos procedentes de los niveles del Cobre Tardío (Fase 22) como del Cobre Final (23a, 23b y 23c), hallados en el corte 6/1c del yacimiento objeto de estudio. La elección de estas fases cronoestratigráficas se debe al interés que presenta comprobar si se han producido modificaciones en la producción cerámica y, por lo tanto, en la relación de estos ítems con actividades económicas concretas en los momentos de tránsito entre el Cobre Tardío (2600-2400 cal a.C) y el Final (2400-2000 cal a.C), momentos en los que se documentan en el yacimiento objeto de estudio profundas transformaciones en las estrategias agropecuarias (Riquelme 1998; Rovira 2007) y se han propuesto importantes cambios sociales en el sur de la península ibérica (Molina et al. 2016).

La adscripción de la cerámica a este período cultural se debe no sólo a la obtención de fechas radiocarbónicas coherentes con el periodo propuesto (Cámara et al. 2016), sino a la presencia de fósiles directores, como es el caso de cerámica con decoración campaniforme, las fuentes y platos de borde biselado y determinadas formas carenadas y recipientes de almacenaje de perfil en S de medias dimensiones (Pellicer y Schüle 1966, 
Arribas y Molina 1979a, 1979b; Arribas et al. 1983, Pellicer 1995, Moreno 1993, Molina y Cámara 2005). Además, la continuidad de estos niveles con otros anteriores y posteriores en la secuencia estratigráfica (Ramos et al. 1997, Cámara et al. 2016) permite asegurar su adscripción. Asimismo, se realizaron algunos estudios de arqueomagnetismo sobre algunas piezas para estimaciones climáticas y poder datar así con más certeza los niveles en los que se encontraron estas cerámicas (Nachasova et al. 2007).

Todas las muestras cerámicas se recogieron de la zona del poblado, procedentes de una vivienda en la que se encontraba un contenedor, en el caso de la Fase 22; de la limpieza de un muro en la 23a; y de niveles de incendio, en el caso de la Fase 23b y 23c, asociados a un muro de fortificación (Cámara et al. 2016). Lamentablemente las acciones de los excavadores clandestinos entre 1974 y 1991 habían afectado considerablemente estos niveles, lo que se tradujo en la limitación del área excavada al mínimo a la hora de proceder al acondicionamiento del sondeo arqueológico para su protección y exposición pública (Ramos et al. 1997) y en la imposibilidad de contextualizar mejor los materiales recuperados, con los consecuentes problemas a la hora de contrastar las funcionalidades propuestas.

\section{TIPOLOGÍA DE LAS CERÁMICAS DEL COBRE RECIENTE DE LOS CASTILLEJOS}

\subsection{Grupos tipológicos de la Edad del Cobre de Los Castillejos}

Con el fin de crear una tipología para la cerámica del Cobre Reciente de los Castillejos, que nos permitiera una mejor caracterización de las razones para la posible variabilidad técnica presente y su relación o no con funciones específicas, se realizó un análisis estadístico (Análisis de Componentes Principales) basado en una serie de variables morfométricas (Vico 2016), siguiendo la estela de estudios precedentes realizados por investigadores del Grupo de Investigación HUM274 (Contreras 1986; Contreras et al. 1987-88; Moreno 1993; Lizcano 1999; Contreras y Cámara 2000; Aranda 2001; Fernández 2011), a partir de aquellos fragmentos que nos ofrecían rasgos que permitían reconstruir su forma. Estas variables son: el diámetro de la boca (DIABO), la altura total del recipiente (ALTO), el diámetro del ensanchamiento máximo (DIAMA), la altura desde el ensanchamiento máximo (ALTMA) y el ángulo del borde (ANGGO). Estas variables facilitan la creación de tipos y subtipos cerámicos, que presumiblemente corresponderán, según sus características, a grupos tecnológicos más o menos específicos. En cambio, si bien se han excluido medidas en nuestro análisis estadístico como las correspondientes a los fondos de la vasija, dado el reducido número de fondos no convexos localizado, los elementos de aprehensión, o los ángulos del cuerpo superior e inferior a partir del ensanchamiento máximo, sí se ha tenido en cuenta la presencia de estos elementos con el fin de caracterizar mejor los elementos analizados e incluso hacer precisiones sobre su presunta función.

Este análisis dio como resultado un total de 15 grupos tipológicos (G.T.) (tab. 1), destacando en número de ejemplares los cuencos semiesféricos (33), cuencos de casquete esférico (9), ollas globulares (6), orzas globulares (1), ollas ovoides (23), orzas ovoides (9), fuentes biseladas (9) y platos biselados (20), que, como se ha dicho, pueden ser considerados los elementos más significativos para poder asentar cronológicamente la tipología aquí estudiada en el Cobre Reciente (Molina y Arribas 1979a, 1979b), los estratos de los que proceden los materiales, junto con las dataciones realizadas, y consecuentemente, los tipos cerámicos obtenidos en el proceso clasificatorio realizado.

Con todo lo anterior podemos observar cómo priman a lo largo de toda la secuencia estudiada las formas simples (fig. 2.), salvo algunas excepciones en algunas ollas, platos y fuentes que introducen carenación en la parte media-alta. Se dan las formas abiertas generalmente en aquellos recipientes que podemos considerar de "mesa", como cuencos, fuentes, platos y vasos. Las formas cerradas se asocian generalmente a formas de cocina (ollas y cazuelas), de almacenaje (orzas), y a un reducido grupo de cuencos (G.T. III). Para terminar, destacamos una quesera de forma troncocónica (G.T. XIV), única en las fases cronoestratigráficas aquí estudiadas.

Además, mediante el análisis visual directo de los fragmentos también pudimos observar una serie de elementos de aprehensión, que sólo están presentes en el $5,85 \%$ de la muestra total y que presentan tipologías diversas: mamelones (de aguijón, cónicos y con perforación horizontal), asas (anulares, de cinta y horizontales) $\mathrm{y}$, en un caso excepcional, un pitorro. Sin embargo, es difícil asociar estos elementos a formas cerámicas concretas dado el pequeño tamaño de los fragmentos en los que han aparecido, que no permiten en casi ningún caso 
Tabla 1. Grupos tipológicos del Cobre Reciente de Los Castillejos.

\begin{tabular}{|c|c|c|c|}
\hline \multicolumn{2}{|r|}{ Grupos tipológicos } & \multicolumn{2}{|r|}{ Tipos } \\
\hline \multirow{3}{*}{$\mathrm{I}$} & \multirow{3}{*}{ Cuencos de pequeño tamaño } & \multicolumn{2}{|c|}{ T.1. Cuencos de casquete esférico } \\
\hline & & \multicolumn{2}{|c|}{ T.2. Cuencos semiesféricos de tamaño muy pequeño } \\
\hline & & \multicolumn{2}{|c|}{ T.3. Cuencos semiesféricos de pequeño tamaño } \\
\hline \multirow{4}{*}{ II } & \multirow{4}{*}{$\begin{array}{l}\text { Cuencos de mediano y gran ta- } \\
\text { maño }\end{array}$} & \multicolumn{2}{|c|}{ T.4. Cuencos de casquete esférico de borde saliente } \\
\hline & & \multicolumn{2}{|c|}{ T.5. Cuencos parabólicos hondos } \\
\hline & & \multicolumn{2}{|c|}{ T.6. Cuencos grandes de fondo plano } \\
\hline & & \multicolumn{2}{|c|}{ T.7.Cuencos semiesféricos de borde vertical } \\
\hline \multirow{3}{*}{ III } & \multirow{3}{*}{$\begin{array}{l}\text { Cuencos de mediano tamaño con } \\
\text { borde entrante }\end{array}$} & \multicolumn{2}{|c|}{ T.8. Cuencos globulares planos } \\
\hline & & \multicolumn{2}{|c|}{ T.9. Cuencos semiesféricos de borde ligeramente entrante } \\
\hline & & \multicolumn{2}{|l|}{ T.10. Cuencos esféricos } \\
\hline \multirow{2}{*}{ IV } & \multirow{2}{*}{ Vasos } & \multicolumn{2}{|c|}{ T.11. Vaso carenado plano con carena media } \\
\hline & & \multicolumn{2}{|c|}{ T.12. Vaso globular con cuello marcado y borde ligeramente saliente } \\
\hline $\mathrm{V}$ & Cuencos grandes semiesféricos & \multicolumn{2}{|c|}{ T.13. Cuenco grande de forma semiesférica } \\
\hline $\mathrm{VI}$ & Platos con borde biselado & \multicolumn{2}{|c|}{ T.14. Plato de forma simple y borde biselado } \\
\hline VII & Fuentes carenadas & \multicolumn{2}{|l|}{ T.15. Fuente carenada } \\
\hline \multirow{3}{*}{ VIII } & \multirow{3}{*}{ Fuentes con borde biselado } & \multicolumn{2}{|c|}{ T.16. Fuente de forma simple y borde biselado } \\
\hline & & \multicolumn{2}{|c|}{ T.17. Fuente hondas de borde biselado } \\
\hline & & \multicolumn{2}{|c|}{ T.18. Fuente grande de forma simple y borde biselado } \\
\hline $\mathrm{XI}$ & Fuentes grandes de forma simple & T.19. Fuente de forma si & \\
\hline $\mathrm{X}$ & Cozuelas bondos & T.20. Cazuela de forma & lar \\
\hline$\Lambda$ & Cazueras homuas & T.21. Cazuela de tenden & arabólica \\
\hline & & T.22. Ollas carenadas & \\
\hline & & T.23. Ollas ovoides pequ & \\
\hline XI & Ullas & T.24. Ollas ovoides & \\
\hline & & T.25. Ollas globulares pl & \\
\hline & & T.26. Orzas ovoides peq & \\
\hline & & & Subtipos \\
\hline XII & Orzas medianas & T.27. Orzas globulares & $\begin{array}{l}\text { a. Orzas ovoides de borde engrosado lige- } \\
\text { ramente marcado y fondo plano en arista }\end{array}$ \\
\hline & & & b. Orzas globulares \\
\hline YUI & Irzes crondos & T.28. Orzas ovoides & \\
\hline AIII & Hzas gianues & T.29. Orza ovoide plana & \\
\hline XIV & Quesera & T.30. Quesera & \\
\hline $\mathrm{XV}$ & Platos carenados & T.31. Platos carenados & \\
\hline
\end{tabular}




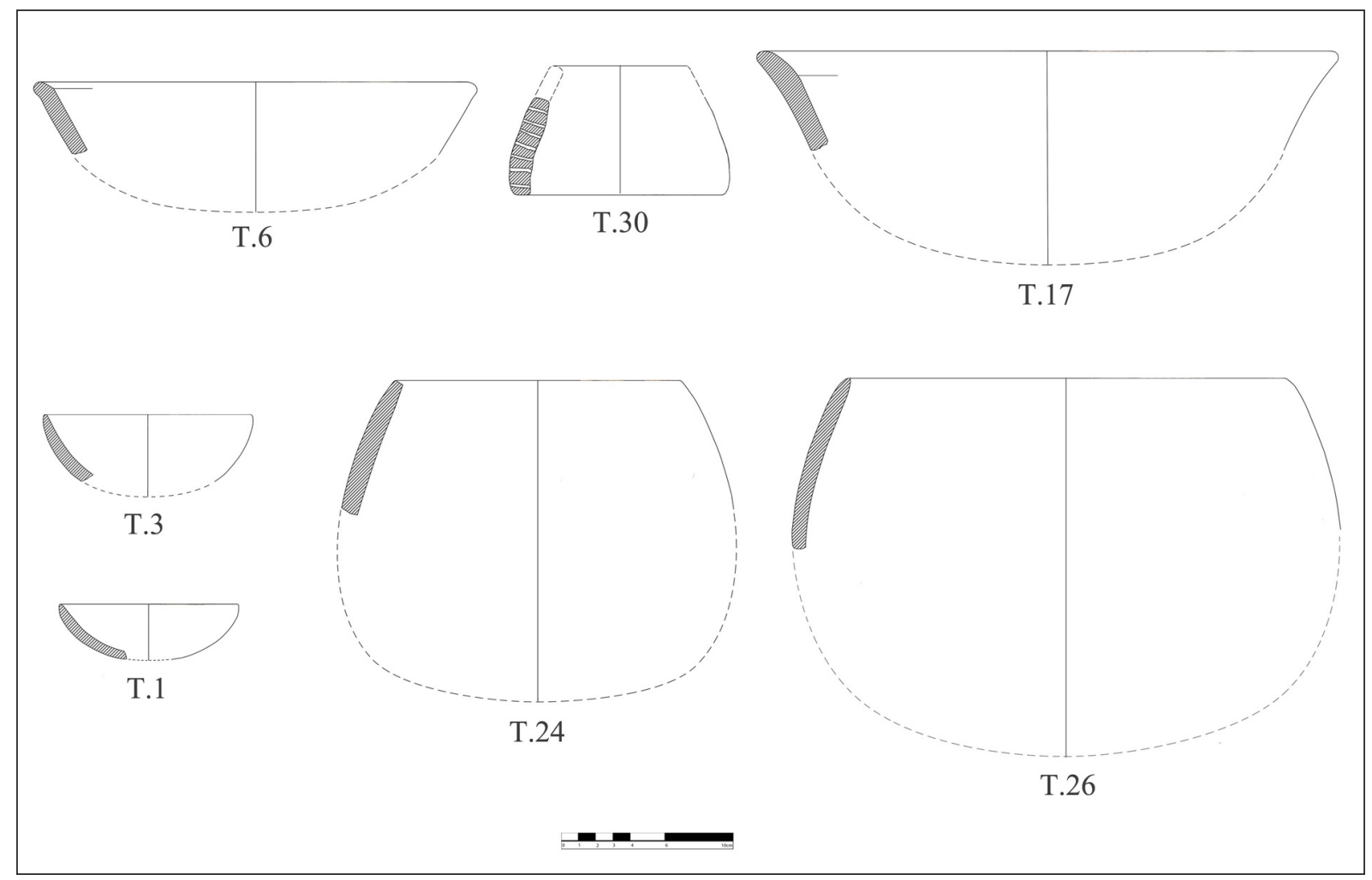

Figura 2. Algunas de las formas cerámicas características del Cobre Reciente de Los Castillejos. Para la descripción de los tipos cerámicos véase tabla 1 .

definir la forma de la vasija. Tan sólo pudimos identificar un mamelón de aguijón en una cazuela y otro de forma indeterminada en una olla.

En cuanto a los fondos, únicamente hemos podido determinar un fondo de anillo y dos fondos planos, estos últimos asociados a un cuenco semiesférico y a una orza respectivamente.

\subsection{Cerámicas decoradas de la Edad del Cobre de Los Castillejos}

En cuanto a las cerámicas decoradas, son particularmente escasas en estos niveles, suponiendo el $9 \%$ de la muestra total estudiada (fig. 3).

Las técnicas decorativas más abundantes en el período que nos ocupa son las impresiones digitadas (fig. 3 f) e incisiones, situadas ambas en los bordes de la vasija. También aparecen, aunque excepcionalmente, perforaciones decorativas en un pie (fig. 3 e).

Asimismo, se han documentado algunos fragmentos con decoración a la almagra, de color rojo vivo, llegando incluso en ocasiones a coloraciones negras debido a la intensidad del fuego durante la cocción. El almagrado puede aparecer sólo por la parte exterior o por ambas cara de la vasija. Hay un interés por el cuidado superficial de este tipo de cerámicas, pues este almagrado se aplica sobre superficies bruñidas o alisadas. La presencia de decoración a la almagra denota una continuidad en la utilización de esta técnica decorativa iniciada en el Neolítico en este mismo yacimiento (Blázquez 2011, Molina et al. 2017b).

Más importante es referir aquellas vasijas que se pueden inscribir en la clase campaniforme, si bien sólo hemos identificado siete ejemplares, que constituyen un 3,15\% del conjunto cerámico total, porcentaje muy escaso si lo comparamos con la concentración en ciertas áreas de los grandes centros de producción de campaniforme en este período en el cuadrante sudeste de la península ibérica, como Los Millares (Arribas et al. 1987, Arribas y Molina 1987, Capel et al. 2001) o el Cerro de la Virgen (Schüle 1980, Molina et al. 2017a).

Este tipo de decoración aparece en la mayor parte de los casos sobre tipos cerámicos típicos del denominado "Horizonte campaniforme", como son los vasos 


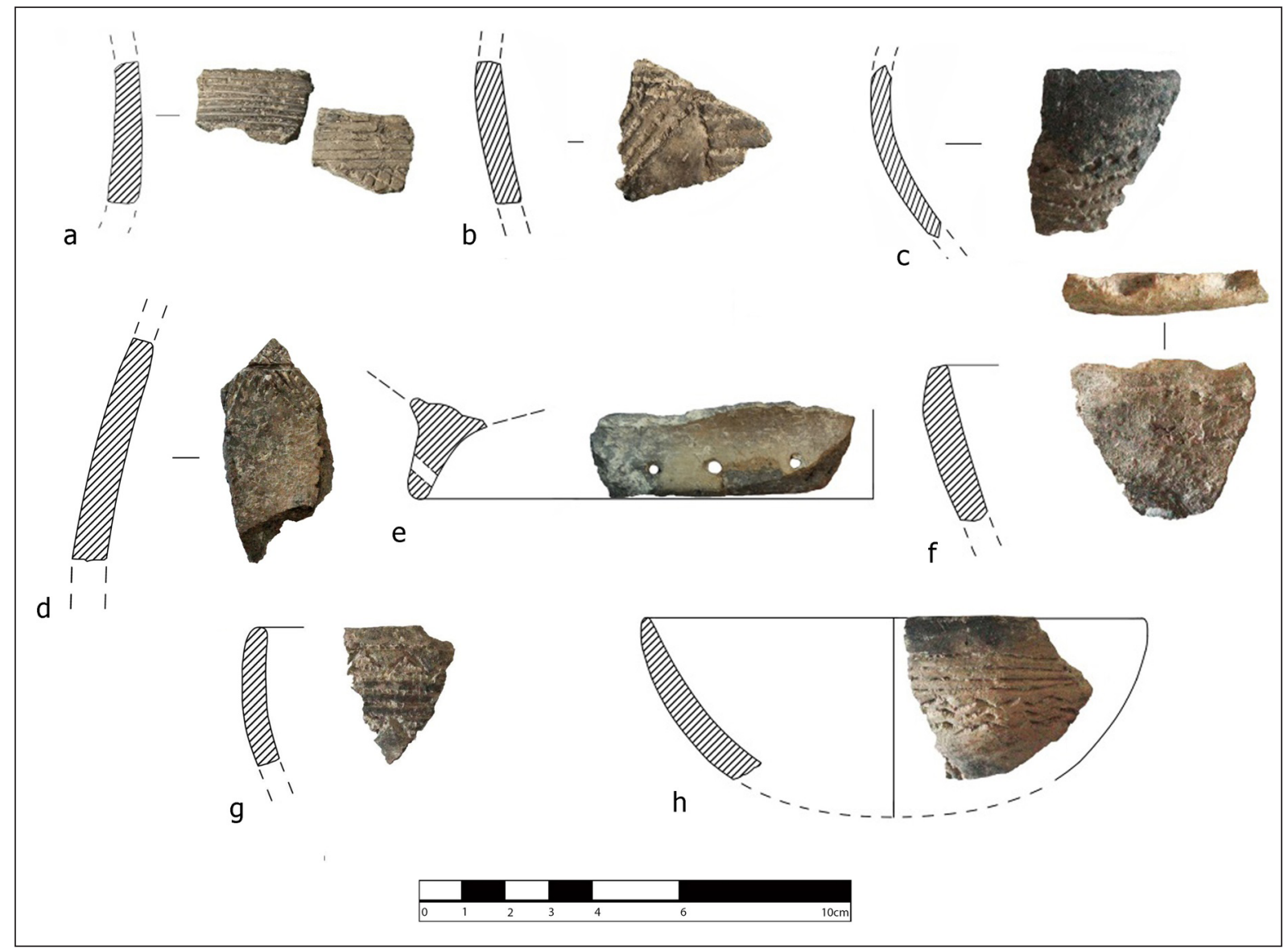

Figura 3. Cerámicas decoradas del Cobre Reciente de Los Castillejos.

y los cuencos, salvando algún fragmento amorfo que no nos ha permitido identificar la forma del recipiente. Las técnicas decorativas que nos encontramos para este tipo de cerámica son incisiones e impresiones, que suelen aplicarse de la siguiente manera: incisiones en la parte externa de la vasija, que dibujan bandas horizontales y enrejado (fig. 3 a) y líneas horizontales y oblicuas (fig. $3 \mathrm{~d}$ ); impresiones a peine que alternan líneas horizontales y en zig-zags (fig. 3 g) o triángulos rellenos de líneas horizontales en la base o triángulos rellenos de líneas oblicuas (fig. 3 b) y, por último, decoración a peine formando guirnaldas (fig. 3 c) (Vico 2016). También se asocian en algún caso las incisiones e impresiones espatuladas con motivos decorativos a base de líneas horizontales y en zig-zags (fig. 3 h). Entre las incisiones todavía se mantiene parte de la pasta blanca que las rellenaba. Además, las superficies sobre las que se aplican estas decoraciones se presentan muy cuidadas, generalmente alisadas y bruñidas.

\section{METODOLOGÍA}

Con el objetivo de obtener mayor información sobre el proceso de producción cerámica llevado a cabo durante el Cobre Reciente de Los Castillejos y el tipo de materia prima empleado en la misma, se han aplicado dos técnicas analíticas: la estereomicroscopía y la difracción de rayos $\mathrm{X}$ (DRX).

Para ello, se escogieron con una primera inspección visual las piezas que, por sus características, podían ser reconstruidas (las utilizadas en el análisis tipológico de carácter morfométrico) más aquellas que presentaban decoración o algún rasgo especial a simple vista, que se podría considerar que tiene relación con algún aspecto tecnológico. Así, para la selección de la muestra se tuvieron en cuenta los siguientes aspectos, expuestos aquí en orden de prioridad: 1. Morfometría; 2. Decoración; 3. Asa, borde y fondo; 4. Tecnología especial; 5. Formas especiales. De esta manera, se eligió una muestra total de 222 fragmentos a analizar: 60 piezas por 
permitir la reconstrucción completa del recipiente y haber sido incluidas en el análisis morfométrico; 13 por la presencia de decoración; 14 por contar con asas u otros elementos de aprehensión; 16 por considerarse formas especiales; 16 por presentar rasgos claramente vinculados con la tecnología; 97 por las características de su borde; 6 por la documentación del fondo.

El primer paso de nuestro análisis ha consistido en la observación a través de lupa binocular o estereomicroscopio de la matriz cerámica de todos los fragmentos incluidos en la muestra. Para ello, se ha utilizado un estereomicroscopio modelo Leica L80 con hasta 7.5X$60 \mathrm{X}$ aumentos, con una cámara acoplada modelo Leica EC3 y objetivo Leica achro $0.5 x$. La captura de imagen se ha realizado con el software Leica Aplication Suite.

Con esta técnica se ha llevado a cabo un estudio macroscópico de la composición y textura de la matriz, obteniéndose información relacionada con determinadas fases del proceso de producción cerámica, así como los gestos técnicos empleados por el productor durante el modelado o el tipo de cocción, entre otras cuestiones. Además, el proceso de análisis permite identificar la posible existencia de diferentes técnicas utilizadas en la fabricación de las vasijas, con lo que se puede llegar a establecer si existe un grado de estandarización de la producción.

Este análisis, en cualquier caso, requiere una contrastación con el empleo de otros medios analíticos, como la DRX, para caracterizar mejor el tipo de minerales que componen la pasta, pues a simple vista es difícil determinar con certeza la naturaleza de los antiplásticos que se hallan insertos en la matriz cerámica. Con esta técnica se pueden identificar las fases cristalinas de los minerales, que se ven reflejadas a modo de picos en un difractograma.

El análisis mineralógico mediante DRX requiere una preparación de la muestra. Esta debe de ser reducida a polvo, por lo que se moltura una pequeña parte de cada fragmento (en torno a $1 \mathrm{gr}$ del mismo) en un mortero de ágata. Se considera que la muestra está lo suficientemente molturada cuando se reduce a menos de 10 micras, lo que se denomina polvo total (Navarro 2008). Con este tamaño se estima que el difractómetro podrá leer correctamente las fases cristalinas de los minerales.

Una vez preparadas las muestras, estas se han analizado en el Centro de Instrumentación Científica de la Universidad de Granada con un difractómetro BRUKER D8 ADVANCE con radiación $\mathrm{Cu}$ (Tubo sellado) y detector LINXEYE. Los parámetros de medición fueron de $2 \mathrm{~s}$ por paso de escaneo, con un incremento de 0.0393766 , con un límite de 2 theta de inicio en 3 y parada en 70,0108 a una potencia de $40 \mathrm{Kw}$ y $40 \mathrm{~mA}$. La obtención de los datos se ha realizado con la ayuda del software DIFRAL plus XRD Commander. Los picos de los difractogramas resultantes han sido leídos a través del software XPowder 12 Versión 2014.04.37, donde se identifican las diversas fases cristalinas de los minerales que componen la pasta cerámica con ayuda de la base de datos PDF2, contrastando los resultados con los proporcionados por la base de datos del Proyecto rruff.info.

Por último, los resultados obtenidos mediante DRX fueron sometidos a un análisis estadístico y se representaron en un diagrama triangular realizado mediante el programa ProSim Ternary Diagram. Este diagrama permite mostrar de forma bidimensional las proporciones de los diferentes minerales contenidos en las muestras analizadas. A partir de las distribuciones de las muestras en los gráficos de los análisis estadísticos, pueden establecerse agrupaciones en el caso de que diferentes individuos presenten similares propiedades mineralógicas, lo que permite definir de manera más clara diferencias y semejanzas tecnológicas entre los fragmentos (Blázquez 2011, Gámiz 2011, Dorado 2012).

Todo este proceso de estudio ha venido acompañado de un análisis pormenorizado del entorno del yacimiento a nivel geológico, posibilitando la determinación de la zona de captación de la arcilla. La comparación de las características mineralógicas de los conjuntos estudiados con las composiciones identificadas en los sedimentos analizados provenientes del entorno, nos ha permitido discriminar aquellas producciones locales de las exógenas, aun con las limitaciones del análisis DRX para la identificación concreta de las materia primas, permitiéndonos elaborar una aproximación a los aspectos relacionados con el intercambio y contacto entre grupos humanos.

\section{TECNOLOGÍA DE PRODUCCIÓN CERÁMICA EN LOS CASTILLEJOS}

\subsection{Grupos tecnológicos: resultados de la estereomicroscopía y el análisis DRX}

En este apartado han sido comparados los resultados obtenidos mediante estereomicroscopía y DRX, con el fin de contrastar las características de la pasta cerámica y su composición mineralógica, y poder observar así si guardan relación entre ellas. Como hemos dicho, las 222 muestras han sido sometidas a estereomicroscopía, mientras que para DRX se seleccionaron 57 piezas (tab. 2) atendiendo a las características previamente identificadas por estereomicroscopía y a los diferentes 
Tabla 2. Resultados semicuantitativos de la DRX aplicada a las muestras correspondientes al Cobre Reciente de Los Castillejos.

\begin{tabular}{|c|c|c|c|c|c|c|c|c|c|c|c|c|c|c|c|c|c|c|}
\hline & Q & $\overline{\mathrm{AL}}$ & DIO & WOL & ALB & ANO & ORTH & MOS & ILL & \begin{tabular}{|l|}
$\mathrm{BIO}$ \\
\end{tabular} & MON & HEM & MAG & \begin{tabular}{|l|} 
GEH \\
\end{tabular} & ANA & DOL & CIN & AMO \\
\hline IF-6228 & 5 & 0,8 & 0,4 & 0,7 & 0,6 & 0,6 & 0,9 & 0,3 & 0,2 & 2,8 & 1,7 & 0,0 & 2,3 & 0,6 & 0,5 & 0,8 & 0,1 & 3,2 \\
\hline 7 & & 5 & & 0,9 & 1,4 & & & 3,2 &, 8 & 9 & & 0,6 & & 2,1 & & 2,6 & 5 & 1,0 \\
\hline & & 6 & & 2,5 & & & & & & 3,7 & & & & 5,3 & & 8 & & 10, \\
\hline $3-1$ & & 3,8 & 9 & 1,7 & 3 & & 3 & & ,5 & 11,5 & & & & כ, & & 1,8 & & , \\
\hline 4 & & 5,5 & 3 & 1,1 & 3 & & 7,7 & 3,5 & 0 & 8,9 & 0,0 & , & & 6 & &, 5 & & , \\
\hline 4 & 4,6 & 10,0 & 3 & 1 , & 1 & & 5,8 & 5,2 &, 5 & 10,2 & 0,5 & 2 & & 1 & 1,3 & 5 & & 7,4 \\
\hline & & $f^{\prime}$, & 2,4 & 1,7 & 1, & & 2,1 & 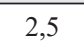 &, 5 & 10,3 & 2,2 & 0,9 & & 1,2 & & 4 & & , \\
\hline & & , & 1,8 & 1, & 1,6 & & 2,0 & $1, i$ & 3 & 4,1 & 1,9 & 0,8 & & 5,3 & 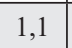 & 2,2 & & I, \\
\hline 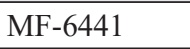 & 0 & 0,8 & 5 & 0,3 & 0,0 & & 1,7 & 1 & 6 & 7,1 & 1,8 &, 0 & 17 & 1,0 & 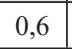 & 1,5 & 03 & 4,6 \\
\hline & 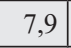 & 4,1 &, 7 & 0,7 & 1, & & 10 & 1,2 & 9 & 7,8 & 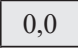 &, 0 & 25 & 1,7 & 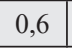 & 0,7 & 0,4 & 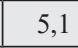 \\
\hline $5-3$ & 2 & 1,6 & 4 & 0,0 & 0,4 & ( 6 & 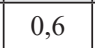 & 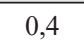 & 5 & 2,6 & 1,0 & 0,1 & 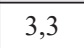 & 1,4 & & 1,0 & 02 & 3,8 \\
\hline $\mathrm{M}$ & 5 & 6,5 & 3 & 1,0 & 2, & 10 & 86 & 2,9 & 4 & 8,0 & - & 0,1 & 30 & 1,0 & 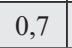 & 0,5 & 05 & 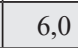 \\
\hline & 2,6 & 1 & 6,7 & 3. & 2 & & 2,0 & & 1,2 & 3,8 & 1,2 & 9 & & 7,4 & & 5 & & 10,9 \\
\hline & 16,3 & 58,0 & 06 & 0 & 2 & & 1,9 & & 0,4 & 6 & 1,2 & 0 & & 2 & & 8 & & 4,8 \\
\hline $\mathrm{MF}$ & 3,1 & 9,0 & 2,0 & 1. & 2 & & 4,4 & 6,1 & 0 & 15,0 & 2 & 0,3 & & 1,4 & & 8 & & 6,6 \\
\hline $\mathrm{MH}$ & 8 & 1,1 & 0,1 & 0 , & 1, & & 4 & & 0,1 & 11,5 & 0,0 & 2 & & 0,7 & 7 & 0,4 & & 2,5 \\
\hline MF-6951-7 & 6,8 & 3,3 & 2,0 & 1,8 & 3,5 & 5,7 & 5,1 & 3 , & 0,2 & 9,5 & 0,1 & 0,7 & 4,3 & 2,1 & 2,0 & 2,5 & 0, & 6,3 \\
\hline MF-6 & 9,2 & 36,4 & 1,9 & 2,7 & 2,0 & & 2,7 & 2, & 0,9 & 8,2 & 2,1 & 1,0 & 4,1 & 3,1 & 3 & 1,3 & & 9,3 \\
\hline MF-6 & 4,4 & 82,0 & 0,7 & 0,4 & 0, & & 0,2 & 1, & 0,5 & 3,6 & 0,0 & 0,7 & 1,9 & 0,7 & 0,5 & 0,2 & 0 & 2,8 \\
\hline MF-6 & 7 & 65,1 & 3 & 0 , & 1, & & 1,8 & 0 & 0,1 & 4,1 & 0,2 & 0,2 & 1,0 & 0,6 & 0,9 & 0,9 & & 3,2 \\
\hline $\mathrm{MF}$ & ,6 & 50,9 & & 1,3 & 2, & & 2,3 & 2,5 & 0,8 & 7,3 & 1, & 0,7 & 0,9 & 0,8 & 0,5 & 1,3 & & 7,0 \\
\hline MF- & 3,4 & 33,7 & 1,0 & 1, & 3 , & 1,0 & 3,8 & 3,5 & 0,5 & 12,1 & 0,0 & 0,3 & ,L & 1,2 & 0 & 6 & 0,4 & 9,2 \\
\hline MF- & 4,6 & 78,0 & 1,1 & 0 & 0, & & 9 & 0, & 0,6 & 4,2 & 1,1 & 0,3 & 1,4 & 0,8 & 0,1 & 0,8 & 14 & 3,1 \\
\hline & 3 & 6 & 0 & & 1 , & & & - & 0,5 & 8,3 & - & 0,3 & 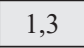 & 0,7 & & 0 & & 5,2 \\
\hline & & & & & & & & & & & & & & ,4 & & & & 5,0 \\
\hline & & 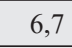 & & & & & & & 1,4 & 15,2 & & & & , & & & & 8,5 \\
\hline & & & & & & & & & & 4 & & & & & & & & 4 \\
\hline & & & & & & & & & & 8, & & & & & & & & 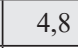 \\
\hline & & & & & & & & & & & & & & & & & & 4,0 \\
\hline & & & & & & & & & & 3,8 & & & & 4,2 & & & & 9,1 \\
\hline & & 6,0 & & & & & & & 1,1 & 12,0 & & & & 1,1 & & & & 0 \\
\hline & & 72,4 & & & 0 & & 1,6 & & 0,1 & 5,8 & & & & 0,5 & & 1,3 & 0,2 & 2,5 \\
\hline MF- & & 6,3 & & 26 & 2 & & 95 & & 2,3 & 4,5 & & 0 & 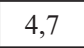 & 7,8 & & 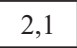 & 0 & 14,3 \\
\hline MF- & 12,9 & 1,0 & 1,0 & 0 , & 1 , & 1 & 15 & 0 , & 0,4 & 3,8 & 0,5 & 0,1 & 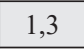 & 0,7 & 0,4 & 0,7 & 0,2 & 2,8 \\
\hline MF-6 & 13,1 & 3 & 1,9 & 1, & 1 , & 1 & 1 & 3 & 0,6 & 6,5 & 1,4 & 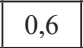 & 5 & 4,0 & 0,8 & 1,4 & 0,8 & 8,2 \\
\hline MF- & 14,2 & 53,3 & 0 & 1,6 & 1 , & 0 , & 10 & 2 & 1,6 & 6,7 & 1,1 & 0,5 & 13 & 2,5 & 0,6 & 2,3 & 0,6 & 6,2 \\
\hline & 7,4 & 68,4 & 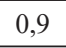 & , & 1 , & & & & 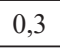 & 6,8 & 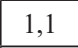 & $\pi$ & 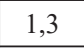 & 1,1 & 0,5 & 0,7 & 0,2 & 4,2 \\
\hline MF-61905-16 & & 50,9 & 0,1 & 1,0 & 0 & & & 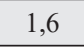 & 0,2 & 6,4 & 0,4 & 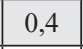 & 2,7 & 1,1 & 0,5 & 0,4 & 0,3 & 5,1 \\
\hline MF-61905-17 & 14,1 & 56,1 & 0,8 & 1,7 & 1,4 & 0,8 & 2,2 & 2,2 & 0,6 & 9,5 & 0,9 & 0,2 & 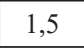 & 1,5 & 0,8 & 0,4 & 0,4 & 5,0 \\
\hline MF-6 & 50,1 & 17,1 & 1,3 & 1,1 & 1,8 & & 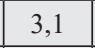 & 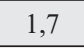 & 1,3 & 6,9 & 1,6 & 0,6 & 7 & 1,3 & $1,$. & 1,0 & 0,3 & 5,8 \\
\hline MF- & 13,0 & 47,0 & 1,7 & 1,0 & 2, & & 1, & 2 , & 1,0 & 11,0 & 1,1 & 0,6 & 4,0 & 2,2 & 1,3 & 0,5 & 0,4 & 7,4 \\
\hline MF-65505 & 16,6 & 51,8 & 1,3 & 1,3 & 1,0 & 0 , & 2 & 2 , & 0,3 & 10,7 & 0,5 & 0,3 & 2,4 & 0,8 & 0,9 & 0,8 & 0,3 & 5,5 \\
\hline
\end{tabular}




\begin{tabular}{|l|c|c|c|c|c|c|c|c|c|c|c|c|c|c|c|c|c|c|}
\hline \multicolumn{1}{|c|}{ N $^{\mathbf{0}}$} & Q & CAL & DIO & WOL & ALB & ANO & ORTH & MOS & ILL & BIO & MON & HEM & MAG & GEH & ANA & DOL & CIN & AMO \\
\hline MF-65507-2 & 12,4 & 58,6 & 1,1 & 0,9 & 1,5 & 0,7 & 2,3 & 2,6 & 0,4 & 9,5 & 0,6 & 0,3 & 1,1 & 0,9 & 1,2 & 1,1 & 0,0 & 4,7 \\
\hline MF-65507-3 & 19,4 & 47,4 & 2,2 & 1,2 & 2,1 & 1,7 & 2,3 & 1,5 & 0,4 & 3,3 & 2,2 & 0,4 & 3,1 & 2,4 & 0,8 & 1,4 & 0,4 & 7,7 \\
\hline MF-65560-1 & 30,9 & 40,8 & 0,6 & 1,7 & 1,8 & 1,9 & 2,0 & 1,2 & 0,4 & 1,6 & 1,7 & 0,9 & 3,0 & 1,9 & 0,6 & 0,8 & 0,6 & 7,7 \\
\hline MF-65564 & 35,6 & 23,7 & 0,1 & 0,0 & 1,7 & 1,5 & 2,6 & 4,5 & 0,8 & 14,1 & 1,5 & 0,6 & 1,0 & 1,0 & 1,3 & 1,4 & 0,2 & 8,3 \\
\hline MF-66774-4 & 13,2 & 61,1 & 0,6 & 1,6 & 0,9 & 0,1 & 1,5 & 1,2 & 0,9 & 5,1 & 2,2 & 0,4 & 2,8 & 0,8 & 0,9 & 1,5 & 0,4 & 4,7 \\
\hline MF-66774-5 & 16,0 & 57,2 & 0,9 & 0,8 & 1,1 & 0,6 & 1,4 & 2,5 & 0,8 & 7,0 & 0,9 & 0,0 & 3,1 & 1,4 & 0,6 & 0,8 & 0,3 & 4,6 \\
\hline MF-66790 & 10,1 & 68,2 & 0,9 & 1,0 & 1,0 & 1,1 & 0,2 & 0,8 & 0,4 & 2,6 & 1,4 & 0,6 & 3,1 & 2,8 & 0,6 & 0,7 & 0,3 & 4,2 \\
\hline MF-66836 & 11,7 & 65,9 & 1,2 & 1,7 & 0,9 & 1,2 & 0,2 & 0,5 & 0,0 & 1,5 & 1,4 & 1,0 & 3,1 & 1,7 & 0,7 & 2,0 & 0,4 & 4,9 \\
\hline MF-66858 & 16,4 & 60,7 & 1,3 & 0,9 & 0,5 & 0,6 & 1,0 & 1,5 & 1,2 & 5,1 & 0,9 & 0,0 & 2,3 & 1,2 & 1,0 & 1,1 & 0,4 & 4,5 \\
\hline MF-66863 & 30,6 & 44,4 & 0,6 & 0,9 & 1,3 & 1,1 & 1,9 & 1,9 & 0,0 & 4,4 & 1,4 & 0,4 & 0,6 & 1,4 & 1,1 & 1,5 & 0,4 & 5,9 \\
\hline MF-610923 & 44,3 & 22,6 & 1,6 & 1,6 & 2,2 & 1,6 & 1,6 & 1,5 & 0,6 & 5,2 & 1,2 & 0,4 & 3,4 & 2,6 & 1,3 & 1,8 & 0,6 & 6,1 \\
\hline MF-610940 & 32,0 & 14,1 & 2,8 & 3,4 & 5,8 & 4,3 & 2,4 & 2,4 & 0,9 & 4,5 & 0,5 & 0,9 & 7,0 & 5,8 & 1,4 & 2,0 & 0,9 & 8,7 \\
\hline MF-611838 & 12,3 & 71,2 & 1,1 & 0,9 & 0,7 & 0,3 & 0,6 & 1,2 & 0,2 & 1,5 & 1,5 & 0,4 & 2,6 & 0,7 & 0,8 & 0,3 & 0,2 & 3,6 \\
\hline MF-611845 & 24,1 & 49,1 & 1,2 & 1,5 & 1,7 & 1,6 & 1,2 & 0,5 & 0,9 & 2,6 & 0,8 & 0,0 & 3,2 & 2,8 & 1,0 & 1,5 & 0,5 & 5,6 \\
\hline MF-613121 & 22,4 & 39,0 & 1,1 & 0,8 & 1,9 & 1,2 & 1,7 & 3,3 & 0,8 & 10,5 & 2,0 & 0,5 & 2,4 & 1,5 & 1,0 & 1,4 & 0,3 & 8,2 \\
\hline
\end{tabular}

tipos de criterios de selección de las muestras antes referidos (morfometría, decoración, etc.), de manera que estuvieran representadas en las muestras para DRX todas las variedades formales de las piezas y todas las variedades técnicas sugeridas a partir del análisis mediante estereomicroscopio.

Así pues, como primer paso, para la agrupación de aquellas cerámicas con características tecnológicas similares, se ha realizado una serie de grupos tecnológicos, utilizando para ello los resultados obtenidos a través de estereomicroscopio. La creación de los grupos tecnológicos se ha basado en unas variables fijas (compacidad de la pasta, frecuencia de aparición de los antiplásticos y tamaño de los antiplásticos), que comparten todos los individuos que se adscriben a cada uno de estos grupos. Por otro lado, dentro de estos grupos pueden diferenciarse subgrupos que presentan en las pastas características mineralógicas propias, es decir, como grupo pueden compartir características tecnológicas similares, pero difieren en la composición mineralógica.

Así, se han podido determinar siete grupos tecnológicos (tab. 3):

\subsection{Caracterización mineralógica de las pastas cerámicas de Los Castillejos}

A partir de los grupos obtenidos, podemos observar que en las cerámicas de Los Castillejos durante el Cobre Reciente destacan fundamentalmente dos tipos de desgrasante mineral: carbonatos y cuarzos.
Como subfases minerales dentro de esos dos grandes grupos minerales encontramos las micas (grupos tecnológicos 1b, 5a y 6) (fig. 4 y 5), que tienden a presentar un tamaño muy fino, cuyo grado de angulosidad sólo podría apreciarse a través de otras técnicas como la petrografía. Entre estas destaca la biotita, aunque a veces encontramos además moscovita $\mathrm{y}$, en casos excepcionales, montmorillonita. En algunos grupos destaca la presencia de plagioclasas, representadas por albita y anortita (tab. 2) que aparecen en aquellas matrices en las que predomina la presencia de cuarzo sobre los carbonatos.

Por otro lado, se han identificado antiplásticos que presentan una coloración roja y otros una coloración negra (grupos tecnológicos 1b, 1c y 5a) (fig. 4 y 5), los cuales requieren de otras técnicas analíticas como la petrografía, la microscopía electrónica de barrido (MEBSEM) o la espectroscopia Raman que nos permitan identificarlos, pues a partir de la observación macroscópica y la DRX resulta imposible profundizar en su caracterización, pudiendo simplemente indicar su presencia.

Es destacable la presencia de esquistos y micaesquistos en algunas de las pastas del Cobre Reciente de Los Castillejos (grupo tecnológico 6) (fig. 5), muy difíciles de encontrar en la geología del entorno de Los Castillejos. En DRX, estas pastas presentan abundancia de cuarzo y micas, siendo estas últimas comunes en las rocas micasquísticas.

Algunos de los minerales que encontramos en las muestras cerámicas parecen indicar la presencia de 
Tabla 3. Tabla con los grupos tecnológicos de Los Castillejos y sus características.

\begin{tabular}{|c|c|c|c|c|}
\hline $\begin{array}{c}\text { GRUPO } \\
\text { TECNOLÓGICO }\end{array}$ & $\begin{array}{l}\text { COMPACTACIÓN } \\
\text { DE PASTA }\end{array}$ & $\begin{array}{l}\text { FRECUENCIA DE } \\
\text { APARICIÓN DE } \\
\text { DESGRASANTE }\end{array}$ & $\begin{array}{c}\text { TAMAÑO } \\
\text { ANTIPLÁSTICOS }\end{array}$ & $\begin{array}{l}\text { TIPO DE DESGRASANTES DEL } \\
\text { GRUPO TECNOLÓGICO }\end{array}$ \\
\hline $1 \mathrm{a}$ & \multirow{3}{*}{ Compacta } & \multirow{3}{*}{$10-20 \%$} & \multirow{3}{*}{$\begin{array}{c}\text { Fino } \\
(<1 \mathrm{~mm})\end{array}$} & Carbonatos \\
\hline $1 b$ & & & & $\begin{array}{l}\text { Carbonatos. Presencia de micas y anti- } \\
\text { plásticos de color rojo y negro }\end{array}$ \\
\hline $1 \mathrm{c}$ & & & & $\begin{array}{l}\text { Carbonatos. Presencia de antiplásticos } \\
\text { de color rojo y negro }\end{array}$ \\
\hline $2 \mathrm{a}$ & \multirow{2}{*}{$\begin{array}{l}\text { Compactación } \\
\text { media o poco } \\
\text { compacta }\end{array}$} & \multirow{2}{*}{$20-40 \%$} & \multirow{2}{*}{$\begin{array}{l}\text { Fino-medio } \\
\text { (hasta } 2 \mathrm{~mm} \text { ) }\end{array}$} & Carbonatos, cuarzo y cuarcita \\
\hline $2 b$ & & & & Carbonatos \\
\hline $3 a$ & \multirow[t]{2}{*}{ Poca compacidad } & \multirow[t]{2}{*}{$30-50 \%$} & \multirow{2}{*}{$\begin{array}{l}\text { Fino-medio } \\
\text { (hasta } 2 \mathrm{~mm} \text { ) }\end{array}$} & $\begin{array}{l}\text { Cuarzo o cuarcita y carbonatos. Presen- } \\
\text { cia de materia orgánica }\end{array}$ \\
\hline $3 b$ & & & & Nódulos oscuros \\
\hline 4 & Compacta & $50 \%$ & $\begin{array}{c}\text { Grueso } \\
\text { (hasta } 3 \mathrm{~mm} \text { ) }\end{array}$ & Chamota \\
\hline $5 a$ & \multirow[t]{2}{*}{ Compacta } & \multirow[t]{2}{*}{$40 \%$} & \multirow{2}{*}{$\begin{array}{l}\text { Fino-medio } \\
\text { (hasta } 2 \mathrm{~mm} \text { ) }\end{array}$} & $\begin{array}{l}\text { Cuarzo, carbonatos y mica. Presencia } \\
\text { de minerales rojos y negros }\end{array}$ \\
\hline $5 b$ & & & & Cuarzo \\
\hline 6 & $\begin{array}{l}\text { Compactación } \\
\text { media }\end{array}$ & $20-30 \%$ & $\begin{array}{l}\text { Fino-grueso } \\
\text { (hasta } 3 \mathrm{~mm} \text { ) }\end{array}$ & Cuarzo, micaesquisto, esquisto y mica \\
\hline 7 & Compactas & $30-40 \%$ & $\begin{array}{l}\text { Medio-grueso } \\
\text { (entre } 1 \text { y } 3 \mathrm{~mm} \text { ) }\end{array}$ & $\begin{array}{l}\text { Carbonatos. Presencia de materia or- } \\
\text { gánica }\end{array}$ \\
\hline
\end{tabular}

temperaturas relativamente altas de cocción, superiores a los $800^{\circ} \mathrm{C}$ (grupos tecnológicos 1a, 2b, 3a, 3b, 5a y 5 b). Esto se deduce del incremento de los valores de minerales que tienden a neoformarse a estas temperaturas, como es el caso del diópsido, la wollastonita y la gehlenita (tab. 2) (Capel et al. 1979). Asimismo, tienden a bajar los valores de carbonatos, hecho que es significativo en este yacimiento si tenemos en cuenta que este tipo de mineral aparece de forma abundante en las cerámicas del yacimiento. Esto se debe a que los carbonatos tienden a fundirse a altas temperaturas, por lo que también es un indicador de este tipo de esfera de cocción (Capel et al. 1979). Por último, junto con estas fases minerales de neoformación aparecen porcentajes relativamente altos de material amorfo (hasta un 14\%) (tab. 2), que son fases minerales cuyo grado de destrucción es tal que no pueden ser detectadas por DRX.

En algunos grupos (Grupos tecnológicos 5b, 3a y $5 b$ ) destaca la presencia de maghemita (tab. 2), mineral que aparece poco en las muestras analizadas. La existencia de este mineral en nuestro estudio induce a pensar que las arcillas utilizadas para este tipo de producción pueden ser de naturaleza férrica.

Otro tipo de producciones que, pese a que no han sido sometidas a DRX ya que no es necesario para caracterizar sus pastas establecer características mineralógicas, sino que a simple vista mediante lupa binocular son perfectamente apreciables, son aquellas en las que se ha empleado como desgrasante principal la chamota o cerámica machacada ex profeso para actuar como desgrasante en la matriz cerámica (Grupo tecnológico 4) (fig. 5).

En otra instancia aparecen las pastas con nódulos negros (grupo tecnológico 3b) (fig. 4). Estos nódulos parecen ser minerales quemados. Las características que a nivel macroscópico presentan algunos de estos nódulos son muy parecidas a las de la chamota, cerámica utilizada como desgrasante que en estos casos ha podido ser calcinada, lo que mejora la resistencia térmica de la cerámica (Chong 2012). El hecho de que planteemos 

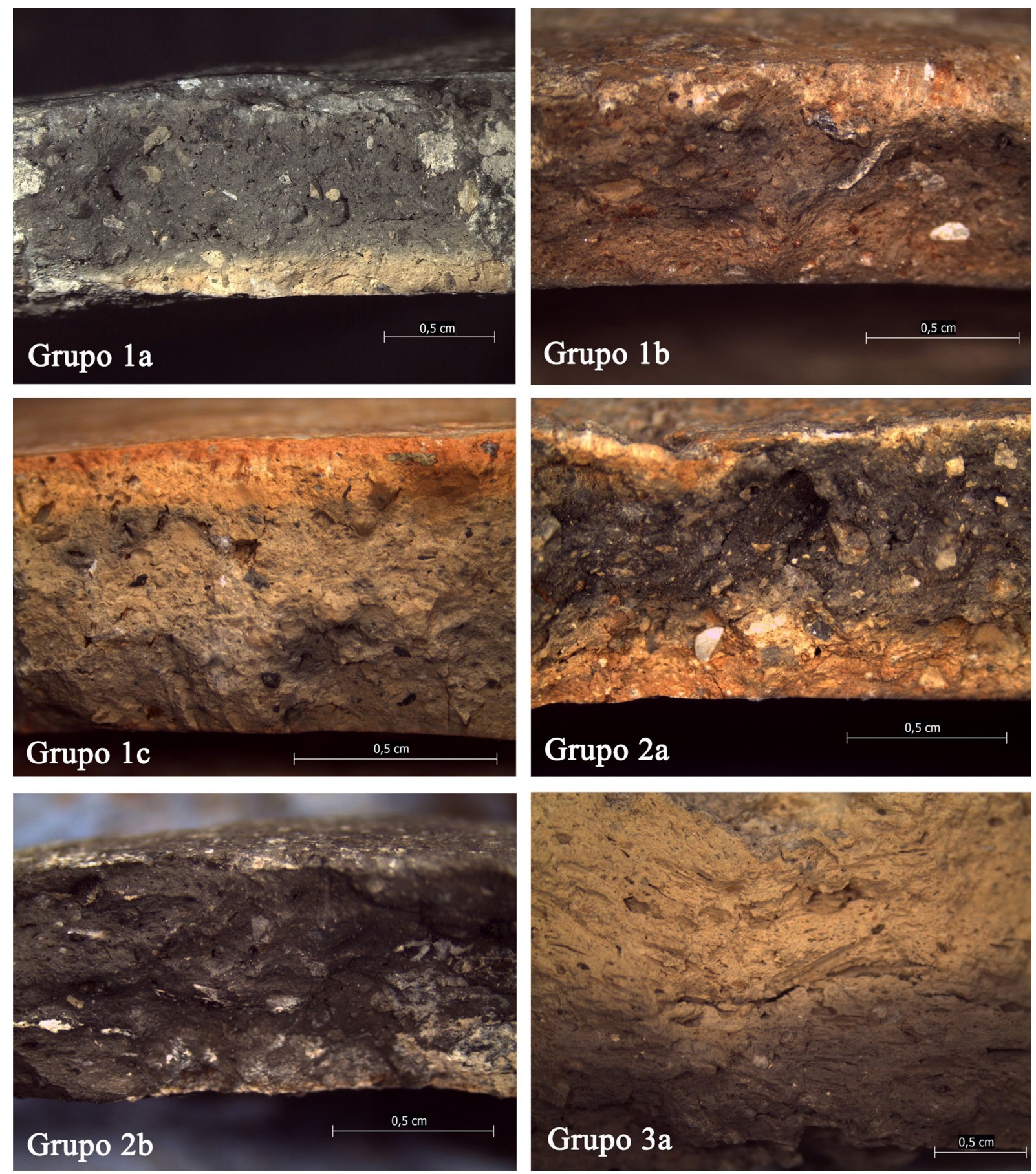

Figura 4. Matrices representativas de los grupos tecnológicos de Los Castillejos.

una posible relación de estos nódulos con lo que tradicionalmente se considera como "chamota" es debido a que estos parecen presentar su propia estructura y antiplásticos, que difieren de las características que muestra la matriz en la que se encuentran insertos, pero esto habría que corroborarlo con otras técnicas más precisas como la petrografía. La teoría de que los considerados como nódulos oscuros pudieran estar quemados contrasta bien con la presencia en DRX de fases minerales que tienden a aparecer a altas temperaturas de cocción. 

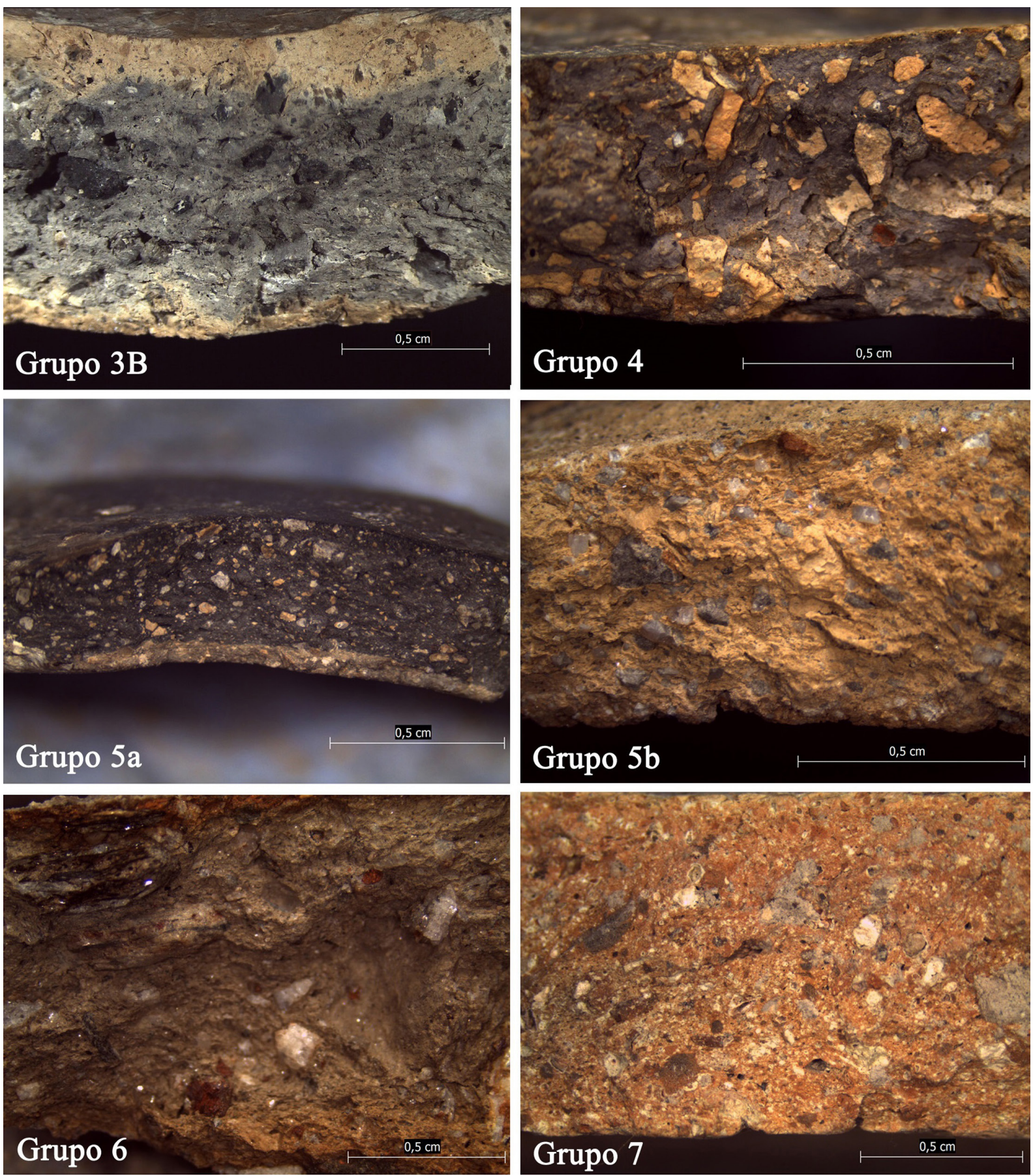

Figura 5. Matrices representativas de los grupos tecnológicos de Los Castillejos.

Por último, y aunque no entre dentro de las características mineralógicas de las pastas cerámicas, pero mostrando su utilidad para diferenciar algunos grupos tecnológicos, aparecen unas pastas en las que el desgrasante principal ha sido la materia orgánica (grupos tecnológicos 7 y 3a) (fig. 4 y 5), que suele aparecer junto con desgrasantes de naturaleza mineral, lo que previene la rotura durante la cocción provocada por el estrés térmico (Chong 2012). Las pastas que contienen este tipo de antiplásticos suelen ser compactas, 
pero porosas debido a la presencia de abundante materia orgánica en estas. Contienen cantidades altas de antiplásticos, que suelen ser de tamaño medio-grueso y presentan forma angulosa. Se debe añadir que de la materia vegetal sólo quedan las improntas de la misma, por lo que deducimos que estas pastas fueron cocidas a más de $750^{\circ}$, temperatura a la que se produce su combustión total (Chong 2012).

\subsection{Características de las pastas cerámicas de Los Castillejos}

Se ha reservado un apartado especial en el que se incluyen aquellas características no determinantes en la creación de grupos tecnológicos, pero si útiles para ampliar información fundamentalmente acerca de determinados gestos técnicos realizados por el productor durante la fabricación de la cerámica, el tipo de materia prima empleada y el tipo de cocción de las vasijas. Para ello vamos a tener en cuenta una serie de factores como marcas en la superficie cerámica, la compactación de las pastas, angulosidad y orientación de los antiplásticos, coloración de las pastas y el tratamiento superficial de las vasijas.

Durante el modelado de la arcilla pueden quedar impresas algunas marcas del proceso. Con esto se puede llegar a conocer el tipo de modelado que se le ha aplicado (García Roselló y Calvo 2013). Generalmente, en aquellas ocasiones en las que las superficies de la vasija no han sido bien acabadas o directamente no se le ha aplicado tratamiento alguno, permanecen impresas las marcas vegetales, fruto de un modelado con molde de cestería (fig. 6). Si bien encontramos en nuestro estudio marcas de molde vegetal, suponiendo

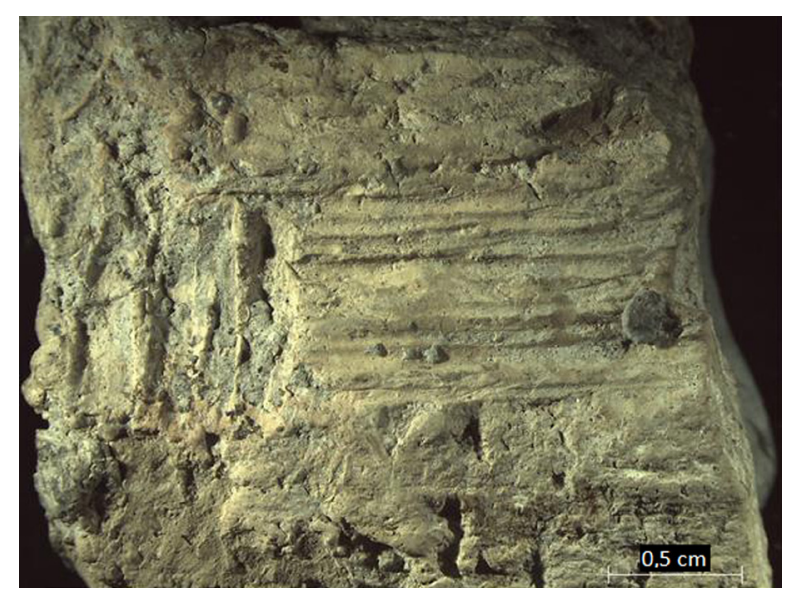

Figura 6. Detalle huella de molde vegetal. solo el $8 \%$ de la muestra total analizada, hay que recordar que la ausencia de este tipo de marcas, como resultado de buenos acabados superficiales, es frecuente en el área de Los Castillejos (Arribas y Molina 1979a) o en el Alto Guadalquivir (Nocete 1994). Por el contrario, la presencia de dichas marcas por la ausencia de tratamiento posterior de las superficies es habitual en ciertas zonas del Sudeste, como en el poblado de Los Millares. También encontramos un $6 \%$ de la muestra con marcas claras de modelado mediante rollos de columbí y un caso excepcional con huellas digitales impresas como testigo del modelado manual de la cerámica por ahuecado. Asimismo, se observan en algunos cuencos, especialmente en los más pequeños, irregularidades en las paredes internas, producto de un ahuecado a partir de una bola de arcilla. En cualquier caso, la aplicación de tratamientos superficiales que pretenden regularizar la superficie cerámica (como el bruñido, el alisado o el espatulado) impiden determinar en la mayor parte de los casos el tipo de modelado empleado, por lo que sólo podemos afirmar la existencia de la aplicación de las técnicas anteriormente mencionadas, sin poder establecer si hay relación entre el tipo de modelado y la forma del recipiente, aunque es muy probable que las fuentes fueran realizadas siempre a partir del molde de cestería.

También hemos detectado marcas de procesos realizados a posteriori, es decir, estas marcas no entran dentro del proceso de fabricación cerámica, pero han sido vistas a través de nuestro análisis macroscópico y deben ser tenidas en cuenta ya que pueden ampliar información acerca de la reutilización de las cerámicas en Los Castillejos. Este es el caso de un lañado o perforación (fig. 7) en la superficie de la vasija, en la que se introducía una grapa con el fin de reparar y así reutilizar los recipientes cerámicos (Gámiz et al. 2013).

El grado de compacidad de las pastas cerámicas varía en función de diversos factores (Gámiz et al. 2013) como la intensidad o el tiempo de amasado que le dedique el productor, cambios bruscos de temperatura durante el secado o la cocción o el tipo de antiplásticos que se hayan incluido en ellas; es decir, la compacidad se reduce cuanto más desgrasante tenga la matriz o mayor sea su tamaño. Por lo general, el grado de amasado de las cerámicas del Cobre Reciente de Los Castillejos es alto, encontrándonos pastas compactas. Ahora bien, en aquellas que presentan mayor número de antiplásticos o clastos de mayor tamaño, la compacidad desciende (fig. 8). Asimismo, en aquellas cerámicas que han sufrido estrés térmico o cambios bruscos de temperatura (Calvo et al. 2004) durante la cocción o el secado 


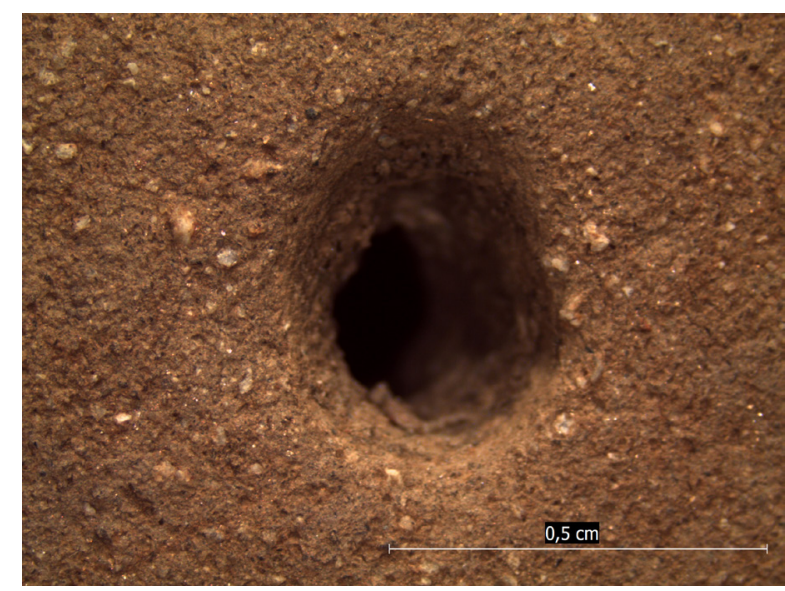

Figura 7. Lañado.

de la cerámica, se observa también un mayor agrietado de las pastas.

En nuestro caso, en el $98 \%$ de la muestra en las que las pastas son compactas, la frecuencia de aparición del desgrasante es baja. Por el contrario, en aquellas pastas en las que la compactación es menor, la aparición de desgrasante supone el $87 \%$, lo que podemos considerar un valor elevado. Asimismo, en aquellas pastas compactas no se han encontrado grandes clastos insertos. Son pastas que, por lo general, están bien depuradas. En cambio, en pastas de compactación media-baja se han encontrado este tipo de inclusiones. Pese a lo anterior, no descartamos que en algunos casos la compacidad de las pastas se vea afectada, como ya se ha dicho en el párrafo anterior, por alteraciones térmicas sufridas durante el proceso de secado o de cocción o, incluso, debido al grado y tiempo de amasado, ya que también se observan pastas compactas con presencia de estrías y poros.

En cuanto a la angulosidad de los minerales, la mayor parte de los analizados mediante estereomicroscopio han presentado formas angulosas, aunque en algunos casos puntuales muestran formas redondeadas, como ocurre con las grandes inclusiones que aparecen en pastas en las que el mineral predominante es fino. En cualquier caso, en aquellas pastas en las que el tamaño de los desgrasantes es muy fino, haría falta aplicar técnicas analíticas, como la petrografía, que permitieran afirmar con exactitud la existencia de ángulos o, por el contrario, formas redondeadas en los antiplásticos. Esto ocurre por ejemplo con las pastas compactas en las que aparece poca cantidad de antiplásticos, especialmente en el grupo tecnológico 1 en el que las pastas presentan predominancia de carbonatos. No es de
1

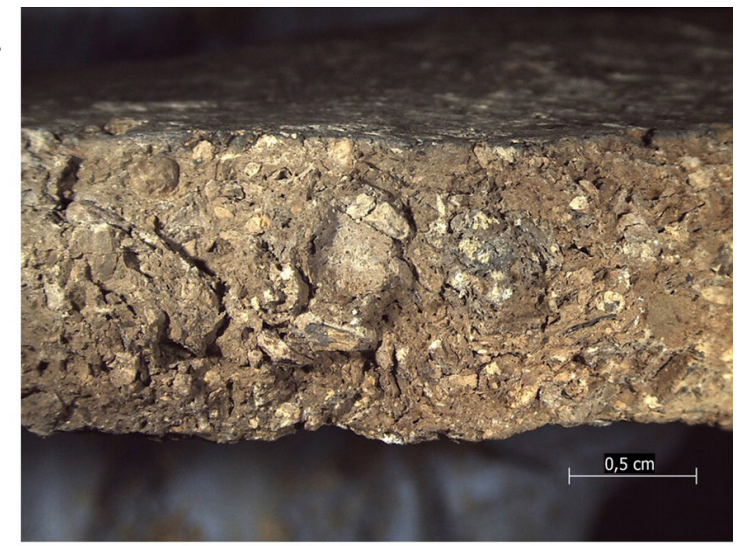

2

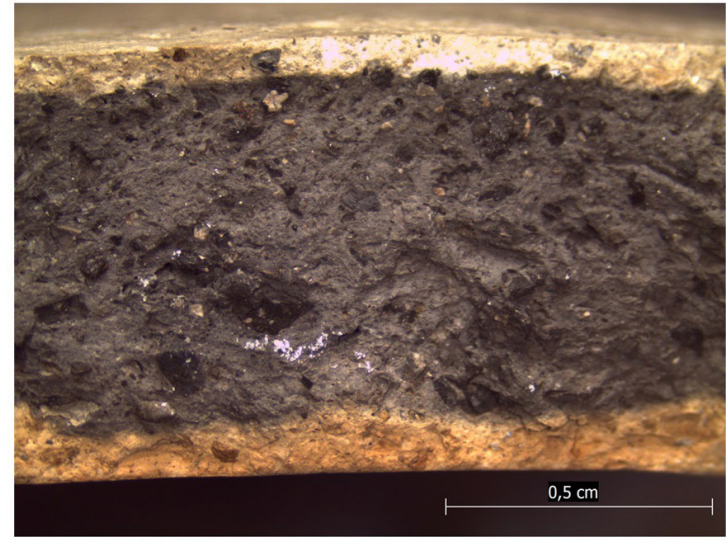

3

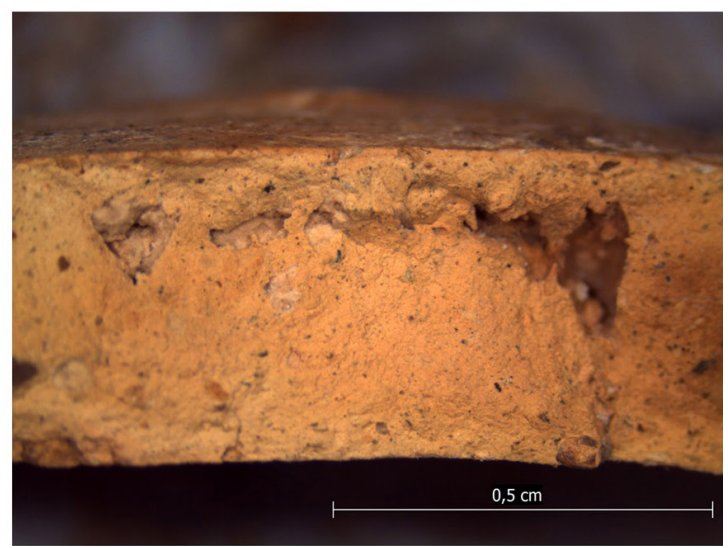

Figura 8. 1- Compactación baja; 2- Compactación media; 3Muy compacta.

extrañar que los carbonatos aparezcan de forma natural en la matriz, pues son frecuentes en el entorno de Los Castillejos, ya que la geología local se compone principalmente de calizas y dolomías. Sin embargo, consideramos que buena parte de los que se encuentran insertos en las pastas fueron utilizados como desgrasantes, debido a sus formas angulosas, de lo que se deduce que 


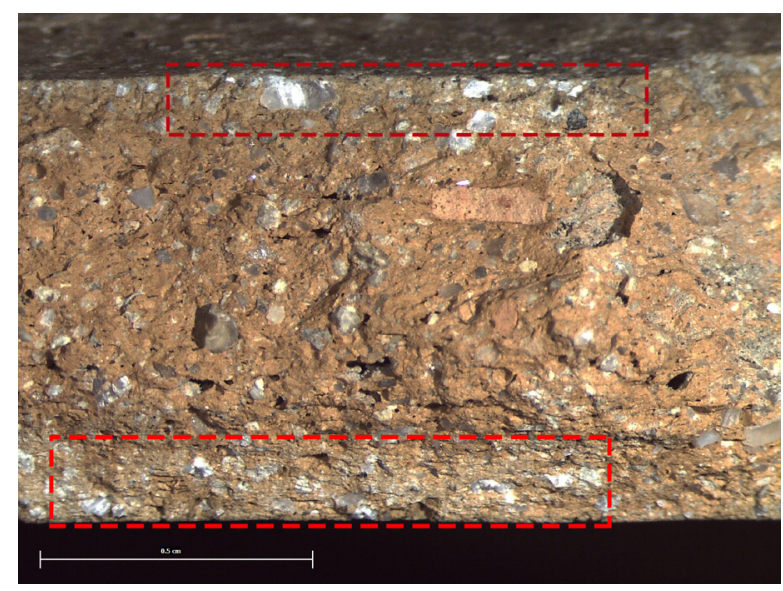

Figura 9. Orientación horizontal de los desgrasantes en las capas exteriores de la matriz al bruñirse la superficie cerámica.

fueron machacados ex profeso para formar parte de las matrices cerámicas.

Por otro lado, hay que indicar que la orientación de los minerales, que puede ampliar información acerca de determinados gestos técnicos del productor a la hora de moldear la arcilla, no puede determinase dado que estos no presentan una disposición ordenada, sino que se disponen de forma desigual en la matriz. Tan sólo en algún caso singular se ha podido observar una orientación clara, como es el caso de algún tratamiento superficial más acusado en el que la disposición de los desgrasantes es horizontal (fig. 9).

Otro aspecto a tener en cuenta es la coloración de las pastas. En Los Castillejos el color predominante es el beige, que es el más frecuente en las pastas de Los Castillejos dada la alta cantidad de carbonatos que hay en el entorno, lo que corrobora la hipótesis anteriormente planteada a través de los resultados de DRX acerca de la abundante presencia de este mineral en las muestras cerámicas del yacimiento objeto de estudio. Pese a lo anterior, también encontramos, aunque en menor medida, la presencia de matrices de color oscuro (negro y pardo), lo que induce a pensar que estas vasijas han recibido un tipo de cocción reductora en la que se consiguió evitar entradas accidentales de oxígeno durante el proceso, bien por la mayor lejanía de la vasija respecto a la superficie del horno, bien el mejor aislamiento de este, de lo que se deduce que la deshidratación de la pasta ha alcanzado prácticamente la pieza entera. Por último, encontramos algunas pastas en las que la coloración predominante es roja-anaranjada, que puede ser debida a la alta presencia de óxido de hierro, como corroboran los resultados de
DRX para estas piezas, mostrando porcentajes estimables de maghemita.

Resumiendo, la cerámica de Los Castillejos presenta tres tipos de cocciones que hemos podido determinar a partir de las coloraciones de sus matrices cerámicas: reductoras, oxidantes y mixtas. Relacionamos aquellas matrices cerámicas de tonalidades claras (beige, grises claros, anaranjados, etc.) con cocciones oxidantes, es decir, la cocción se ha llevado a cabo con presencia de oxígeno en algún punto del proceso. Por el contrario, aquellas coloraciones correspondientes con tonalidades más oscuras y pardas se relacionan con ambientes reductores. En tercer lugar, tendríamos las cocciones mixtas donde el esquema de coloración presentado en las distintas matrices suele estar compuesto por un núcleo de tonalidades oscuras y un área interna y externa y márgenes de tonalidades más claras, que es resultado del poco control de la entrada de aire en las estructuras de horno. En cualquier caso, además del tipo de atmósfera generado durante la cocción, también interfiere en este tipo de cromatismo la posición que ocupe la vasija en el horno, el tiempo de cocción y la temperatura alcanzada durante la misma. De este modo, cocciones más prolongadas aumentan la posibilidad de generar matrices más oscuras, mientras que aquellas cerámicas de coloraciones más claras se relacionan con tiempos de cocción más reducidos. Otro aspecto a tener en cuenta es el éxito durante la fase de secado, ya que la presencia de un exceso de agua contenida en la matriz puede dar lugar a cocciones con mayor presencia de oxígeno, provocando así la fractura de las vasijas en el peor de los casos. Por último, señalaremos que un proceso brusco de enfriamiento de la vasija al extraerla del horno provoca un shock térmico al entrar en contacto con el oxígeno, lo que daría lugar a un aspecto oxidante en la capa exterior de la vasija (García Roselló y Calvo 2006).

Para finalizar, hemos tratado de definir las técnicas más usadas en el último proceso de manufactura de las vasijas antes de la cocción, como son los tratamientos superficiales de las cerámicas (fig. 10). Así, hemos detectado que el tratamiento superficial que reciben la mayoría de las cerámicas es el bruñido, tanto al exterior como al interior de las mismas, pudiéndose sustituir en ocasiones al interior por el alisado, estando presente tanto en aquellas vasijas con decoración como en las que carecen de ella. Esto denota un interés por cuidar las superficies que puede deberse a dos factores: $\mathrm{o} \mathrm{bien}$ a una necesidad de cerrar los poros, lo que confiere a la superficie cerámica impermeabilidad y antiadherencia (Echallier 1984) o, por otro lado, simplemente a un interés estético. Nosotros nos inclinamos a pensar en ambas 
1
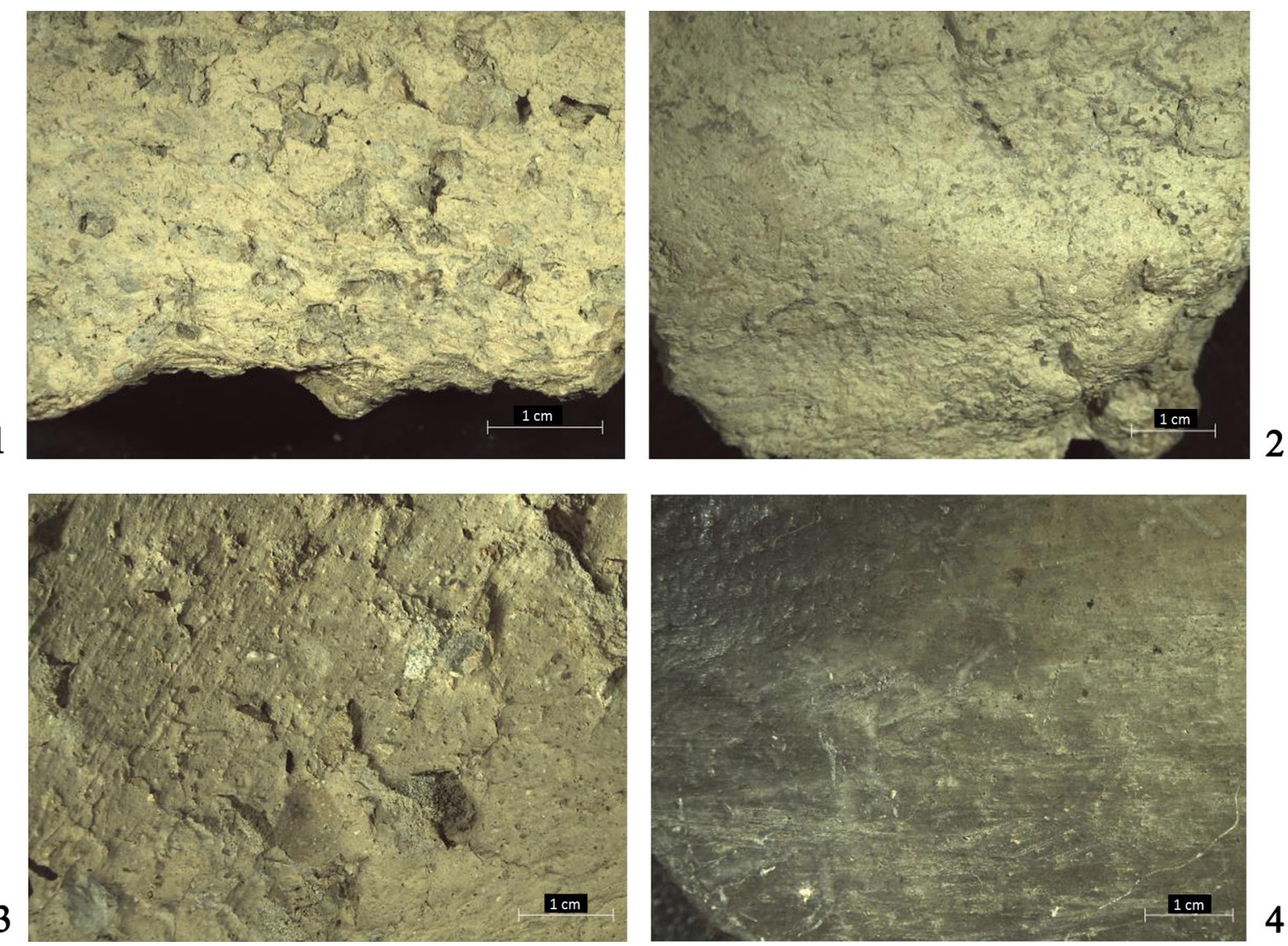

Figura 10. Tratamientos superficiales de las vasijas del Cobre Reciente de Los Castillejos: 1- grosero; 2-alisado; 3-espatulado; 4-bruñido.

razones, pues al aplicarse el bruñido en ambas caras, incluyendo la interior no visible, se infiere que conocían la capacidad de esta técnica para crear una capa protectora en la superficie cerámica que, además, le confería un brillo especialmente relevante en el exterior visible. Otra técnica superficial muy recurrente en Los Castillejos es el alisado, que puede darse tanto al exterior como al interior de la vasija. También aparecen, aunque en menor medida, casos con ambas superficies espatuladas y groseras, estas últimas halladas generalmente en tipos cerámicos vinculados al almacenaje de alimentos, como las orzas. El tipo de espatulado que se aplica en las vasijas objeto de estudio casi consigue el efecto del bruñido debido a la fuerza con la que se aplica el instrumento.

\section{RESULTADOS Y DISCUSIÓN}

La caracterización tecnológica de las cerámicas adscritas al Cobre Reciente de Los Castillejos se ha realizado partiendo de dos técnicas analíticas de base: estereomicroscopía y DRX. Los resultados obtenidos en estos procesos analíticos nos han permitido determinar $\mathrm{y}$ organizar una secuencia de producción de la cerámica para el periodo objeto de estudio.

En primer lugar, hemos podido determinar que la zona de captación de la materia prima de Los Castillejos puede proceder del entorno de Las Peñas. Esto se debe a que, en nuestro análisis macroscópico, hemos detectado en la mayor parte de los casos una coloración beige, característica de arcillas con un alto contenido en carbonatos. Sin embargo, encontramos algunas matrices que reflejan coloraciones rojas, para las cuales los resultados de DRX han aportado presencia de maghemita en ellas, lo que nos indica que la arcilla empleada es férrica. Estas pueden proceder de la extracción de arcillas rojas para la fabricación cerámica, las cuales se encuentran en zonas puntuales de la geología del entorno del yacimiento, asociadas a margas y margocalizas de color rojizo IGME (1985-87). 
En lo referente a la preparación de la arcilla, esta parece depurarse para evitar grandes inclusiones, pues presenta antiplásticos de tamaño fino-medio en la mayor parte de los casos, salvo alguna intrusión de mayor tamaño que aparece de forma esporádica. Por otro lado, creemos que la mayor parte de los antiplásticos que conforman las pastas fueron añadidos, ya que su angulosidad, la cantidad en la que aparecen, su presencia prácticamente exclusiva como desgrasante y la uniformidad de tamaños, así nos lo indica. Además, mediante lupa binocular hemos constatado la presencia de chamota como desgrasante por lo que, junto con lo anterior, inferimos una intencionalidad durante el Cobre Reciente por añadir desgrasantes que reduzcan la plasticidad de la arcilla para facilitar su modelado por un lado, y por otro que doten al producto final de una serie de cualidades ligadas a la resistencia mecánica y térmica con la adición de materiales fundentes y/o refractarios.

Para el modelado de la vasija, se han documentado tres tipos de técnicas: urdido, ahuecado y molde (en nuestro caso este es de naturaleza vegetal). Las diferentes formas de modelado han sido extraídas gracias a las huellas que han dejado este tipo de técnicas en la superficie cerámica (digitaciones, marcas de rollos de columbí e improntas de molde).

Las pastas de las cerámicas de Los Castillejos, en este periodo, tienden a ser compactas o de compactación media, por lo que podemos inferir que han recibido un grado de amasado óptimo, fruto de una intensidad y un tiempo de amasado adecuados. Sin embargo, en casos excepcionales, encontramos pastas de poca compacidad que suelen presentar abundancia de poros y estrías. El grado de compactación viene dado en buena parte de los casos por la mayor o menor presencia de antiplásticos, siendo más compactas aquellas pastas más escasas en estos y viceversa. Pese a esto, también han podido sufrir fracturas debido a cambios bruscos de temperatura (estrés térmico) (Calvo et al. 2004) o a un trabajo deficitario durante al amasado o a un secado insuficiente, lo que ocasiona que el agua excedente contenida en la pasta genere fracturas en el interior de la matriz al elevar su temperatura durante la cocción.

La temperatura de cocción en las producciones durante el Cobre Reciente en este asentamiento no supera los $800^{\circ} \mathrm{C}$, salvo algunos casos en los que alcanzan dicha temperatura o la sobrepasan ligeramente al observarse fases minerales neoformadas en las difracciones realizadas en algunas muestras. A esto hay que añadir que tanto las pastas como las superficies de las vasijas presentan diferentes coloraciones, que infieren una cocción mixta en la mayor parte de la muestra, alternando un cambio de atmósfera oxidante a reductora. Esto se puede deber al uso de estructuras de combustión rudimentarias, que no permiten controlar las temperaturas ni el tiempo de cocción (Gosselain 1992, Livingstone 2001, Kingery 1997), consistentes en hoyos excavados en el suelo u horneras, cubiertos probablemente de combustible orgánico, que permite la entrada de oxígeno durante el proceso (Orton et al. 1997).

Para concluir con los datos obtenidos a través de estereomicroscopía, se constata en las cerámicas objeto de estudio un buen tratamiento superficial, siendo el bruñido y el alisado las técnicas más empleadas, aplicándose estas antes de la cocción, cuando la cerámica se halla en estado de cuero y todavía permite ser modificada. A nivel funcional, no podemos afirmar con certeza que el bruñido actuara como elemento impermeabilizador o antiadherente, ya que se encuentra en la mayor parte de la tipología cerámica aquí estudiada, tanto en recipientes destinados al contenido de líquidos o sólidos, como en vasijas destinadas a actividades de cocina. Sin embargo, sí se observa una pequeña diferencia con respecto a los contenedores de almacenaje como las orzas, que presentan en su mayor parte superficies alisadas y en pocos casos groseras, en las que pudieron prescindir de tratamientos de mayor calidad al no contener líquidos.

En cuanto al análisis mineralógico, los resultados cualitativos y semicuantitativos obtenidos mediante DRX han sido introducidos en un diagrama triangular (fig. 11). Con este diagrama se pueden observar al menos dos zonas de extracción de materia prima claramente diferenciadas, que se observan en todas las fases objeto de estudio $(22,23 \mathrm{a}, \mathrm{b}$ y c): una con abundancia de cuarzo y feldespatos (grupo 1), pero reducida cantidad de carbonatos y otros minerales; y otra con abundancia de carbonatos y otros minerales, pero con poco cuarzo y feldespatos (grupo 2), que concentra la mayor parte de la producción cerámica de Los Castillejos durante el período que nos ocupa. La creación de estos dos grupos que podemos ver en el diagrama triangular, donde básicamente la diferencia se halla en la mayor o menor cantidad de carbonato cálcico y otros minerales o de cuarzo y feldespatos, podría hacernos creer que esté determinada por la destrucción de este carbonato durante la fase de cocción. Efectivamente, la destrucción del carbonato cálcico (principalmente calcita, pero también dolomita) se constata en todos los casos correspondientes a los individuos integrantes del grupo de los cuarzos y feldespatos (grupo 2) representado en el diagrama triangular, conclusión a la que llegamos tras observar los valores de las fases que hemos considerado indicativas de alta temperatura (diópsido, 


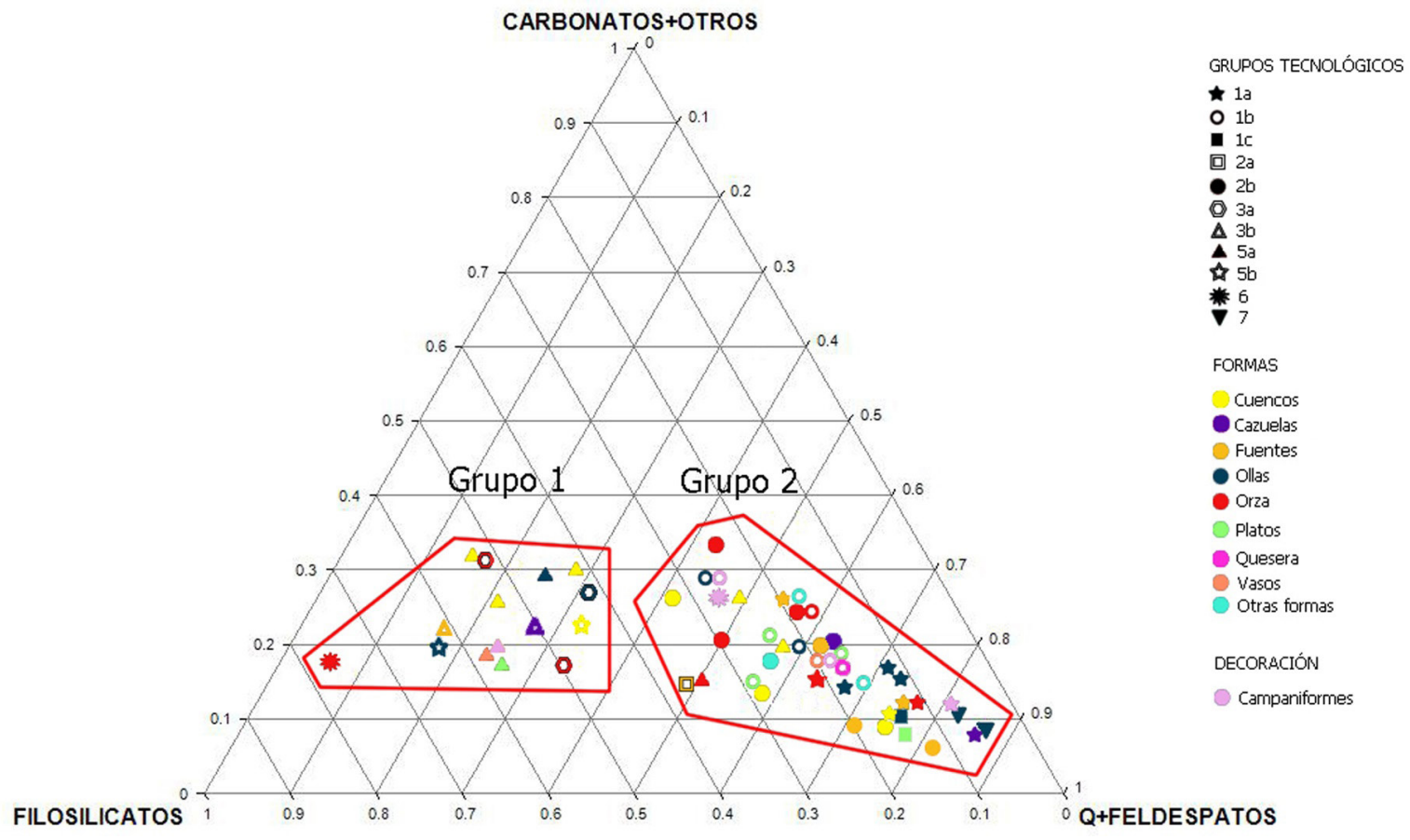

Figura 11. Diagrama triangular con grupos tecnológicos, tipología y decoración cerámica. Grupo 1- Grupo con abundancia de cuarzo y feldespatos; Grupo 2- Grupo con abundancia de carbonatos y otros minerales.

wollastonita y gehlenita). Si bien esta destrucción se efectúa, el mineral mayoritario en el grupo sigue siendo el cuarzo, ya que, aunque antes de la cocción tuviera contenido en carbonato cálcico, este sería secundario en relación con las cantidades del primero.

La hipótesis de que el diagrama triangular nos está discriminando áreas de captación es la más plausible, frente a la posibilidad de que el grupo con mayor representatividad de cuarzos y feldespatos se hubiera formado únicamente por la destrucción del carbonato cálcico a temperaturas superiores a $800^{\circ} \mathrm{C}$.

$\mathrm{Si}$ profundizamos en la procedencia de los minerales que hallamos en DRX, detectamos en nuestro análisis mineralógico que todas las muestras presentaban, en mayor o menor medida, calcita y cuarzo, minerales que se hallan fácilmente en la geología del entorno de Los Castillejos. Las rocas y sedimentos con presencia de carbonatos se presentan en el mapa del IGME (198587) a escasos metros del poblado. Un posible origen estaría en las margo-calizas, que se componen principalmente de calcita y arcillas, lo que permite deducir que las áreas de captación de la materia prima estuvieron cercanas al yacimiento. También pueden proceder de otro tipo de rocas, como las calcarenitas y las dolomías, que también cuentan con proporciones altas de carbonato cálcico. Asimismo, encontramos arcillas $\mathrm{y}$ arenas formadas por el arrastre de materiales (coluviones) y conglomerados, que se hallan próximas a los ríos que discurren cerca de Los Castillejos y que pueden contener de igual manera este tipo de materiales.

La abundancia de este tipo de minerales en las pastas puede estar relacionada con las propiedades que poseen, beneficiosas para determinadas fases del proceso de producción cerámico, y que pudieron motivar el empleo de arcillas o rocas con altos niveles de carbonatos por parte de los productores de Los Castillejos de manera intencionada. El uso de carbonatos como desgrasantes tiene la cualidad de disminuir la plasticidad de la arcilla para facilitar el modelado y la contracción de la vasija durante la fase de secado (Duitama et al. 2004, Livingstone 2007). Por otro lado, los carbonatos también son fundentes, característica que dota a los recipientes de resistencia térmica y resistencia mecánica.

El cuarzo, que también se halla de forma abundante en las pastas cerámicas aquí estudiadas, proporciona cierta resistencia mecánica a la vasija, que disminuye la contracción de la pasta cerámica durante el proceso de secado (Albero 2011, Linares et al. 1983) 
Por último, hay que indicar la existencia de un pequeño porcentaje de mica. Esta la consideramos aquí como componente de la materia prima, que puede proceder del arrastre de materiales ya que aparece en tamaños dispares, normalmente pequeños y con formas redondeadas.

Finalmente, se ha intentado establecer una relación entre la forma del recipiente y la tecnología empleada para su fabricación. Sin embargo, a partir de los resultados obtenidos mediante el diagrama triangular (fig. 11) es difícil asociar una determinada producción a unas formas o tamaños concretos de recipientes, pues las características mineralógicas de las cerámicas se muestran de forma desigual. En ambos grupos se observan tanto formas de pequeño tamaño (con medidas de hasta $12 \mathrm{~cm}$ de diámetro máximo y de hasta $5,8 \mathrm{~cm}$ de altura total) como grande (hasta $50 \mathrm{~cm}$ de diámetro máximo y $30 \mathrm{~cm}$ de altura total) y de tipología diversa (cuencos, platos, fuentes, ollas, orzas, cazuelas, una quesera y otras formas). No obstante, únicamente hemos detectado en dos casos correspondencia entre la función del recipiente y la manufactura cerámica:

1) Orzas: presentan desgrasantes vegetales, que se han identificado mediante estereomicroscopía y que no se han incluido en el diagrama triangular dada su naturaleza no mineral. Se presentan de manera abundante (grupo tecnológico 3 a y 7), por lo que hemos intuido que fueron añadidos. Este tipo de desgrasantes se da mayoritariamente en aquellos recipientes que no van a ser destinados al procesado de alimentos, como es el caso de las orzas, pues una matriz con abundancia de materia orgánica produce unas pastas porosas más aptas para la conservación de sólidos y líquidos.

2) Vasos con decoración campaniforme: presentan pastas por lo general carbonatadas, salvo un fragmento que presenta micaesquisto. Además tienden a mostrar matrices compactas y con poca aparición de desgrasantes, lo que se relaciona directamente con una intencionalidad de tener arcillas depuradas que faciliten el modelado de las vasijas y su posterior decoración. El hecho de que en estas producciones aparezcan carbonatos como mineral más abundante guarda relación con las características de estas inclusiones comentadas con anterioridad.

\section{CONCLUSIONES}

La composición de las matrices cerámicas de Los Castillejos, formadas fundamentalmente por carbonatos y cuarzo, infiere que las áreas de captación de materia prima para la fabricación de las cerámicas del Cobre Reciente de Los Castillejos se encuentran en el entorno del yacimiento, por lo que estamos ante producciones de carácter local. Únicamente debemos considerar aparte un grupo reducido de fragmentos que presentan en su composición esquisto y micaesquisto (grupo tecnológico 6), inclusiones que aparecen de forma redondeada en las pastas, de lo que se deduce que son naturales del sedimento extraído para la fabricación de la cerámica, lo que nos sugiere que no han sido molturados para su adición a las matrices arcillosas.

La presencia de estas rocas no es frecuente en la producción cerámica de Los Castillejos y es muy puntual en la geología del entorno de este yacimiento. Algunos autores proponen que este tipo de material se extrajo de zonas cercanas a Sierra Nevada (Ruiz Bustos 1979), zona de abundantes rocas metamórficas. Esto nos llevaría a plantearnos la aloctonía de las vasijas que presentan este tipo de antiplásticos ya que, además, estos se encuentran en formas cerámicas atípicas de Los Castillejos durante el Cobre Reciente, como es el caso de un plato carenado, único ejemplar hallado en este período, un fragmento con decoración campaniforme de líneas oblicuas y horizontales que difiere del resto de decoración campaniforme hallada en Los Castillejos para los últimos momentos del Cobre, un fragmento de cerámica recortado y perforado y una orza (Vico 2016).

Sin embargo, nos planteamos que procedieran del entorno del yacimiento si nos basamos en el mapa geológico de Montefrío IGME (1985-87), donde se pueden observar pequeños afloramientos de rocas de origen metamórfico (fig. 12) que inducen a pensar que los esquistos y micaesquistos puedan proceder de estos.

Ante los datos expuestos, nos situamos ante la posibilidad de que estos materiales sean o bien autóctonos o bien alóctonos. El hecho de que existan afloramientos cercanos de micaesquisto hace inclinar la balanza hacia una producción autóctona, junto a lo inoperante que resultaría la captación de materia prima en zonas a 60 km del yacimiento, como es el caso de Sierra Nevada. Sin embargo, que estos materiales representen sólo el $2 \%$ de la muestra estudiada y dada la excepcionalidad de los elementos realizados con esta materia prima, refuerza la hipótesis de que estas producciones sean foráneas. Para resolver estas cuestiones, se precisaría un estudio en profundidad de las cerámicas de Los Castillejos, por ejemplo comenzando con análisis de fluorescencia de rayos $\mathrm{X}$ (FRX), que, junto con un estudio pormenorizado de la geología del entorno del yacimiento y la comparación entre producciones cerámicas de otros asentamientos cercanos a este, en los que 


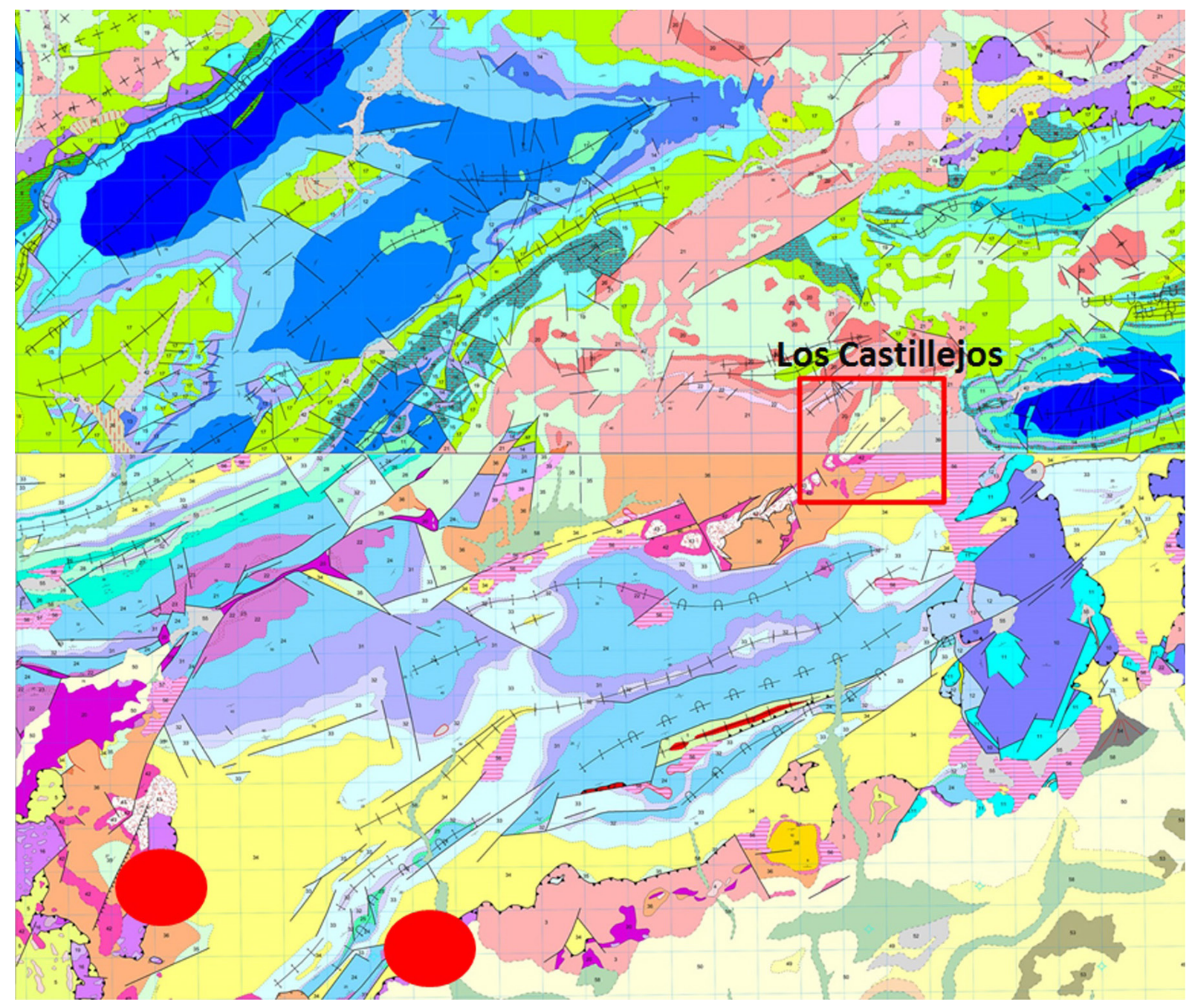

Figura 12. Mapa geológico de Montefrío IGME (1985-87). Los círculos en rojo señalan las zonas de material metamórfico.

el empleo de este tipo de desgrasantes pudiera ser más frecuente debido a la materia prima que les ofreciese el medio natural, podrían ayudar a plantear modelos de circulación de materias primas y, sobre todo, artefactos, entre yacimientos más o menos alejados.

Por otro lado, no se pueden aseverar diferencias tecnológicas a nivel diacrónico entre los períodos que conforman el Cobre Reciente (Cobre Tardío y Cobre Final), ya que no existen cambios significativos en los patrones de producción de un período a otro. Sin embargo, sí se observan pequeñas variaciones con respecto a la tipología (fig. 13), incrementándose durante el Cobre Final (Fase 23) los recipientes de mayor tamaño como orzas, platos y fuentes, además de vasos, y disminuyendo los cuencos en este período, mientras que en el Cobre Tardío (Fase 22) esta última era la forma predominante
(Vico 2016). Asimismo, durante el Cobre Final se observa el paulatino incremento de formas compuestas, que presentan fundamentalmente carenas en la parte media o superior de las vasijas.

Para concluir, se aprecia a partir de todo lo expuesto anteriormente, cierta pericia por parte de los productores cerámicos de Los Castillejos durante el periodo cronocultural que aquí nos ocupa, pues sabían aplicar una determinada tecnología de producción a la cerámica (depuración de la arcilla, conocimiento de las propiedades de determinados desgrasantes como los carbonatos, cuidados tratamientos superficiales, etc.). Sin embargo, a pesar de que hubiera una secuencia de producción lineal para la obtención de recipientes cerámicos (extracción de la materia prima, preparado de la cerámica, secado y cocción), no creemos que 


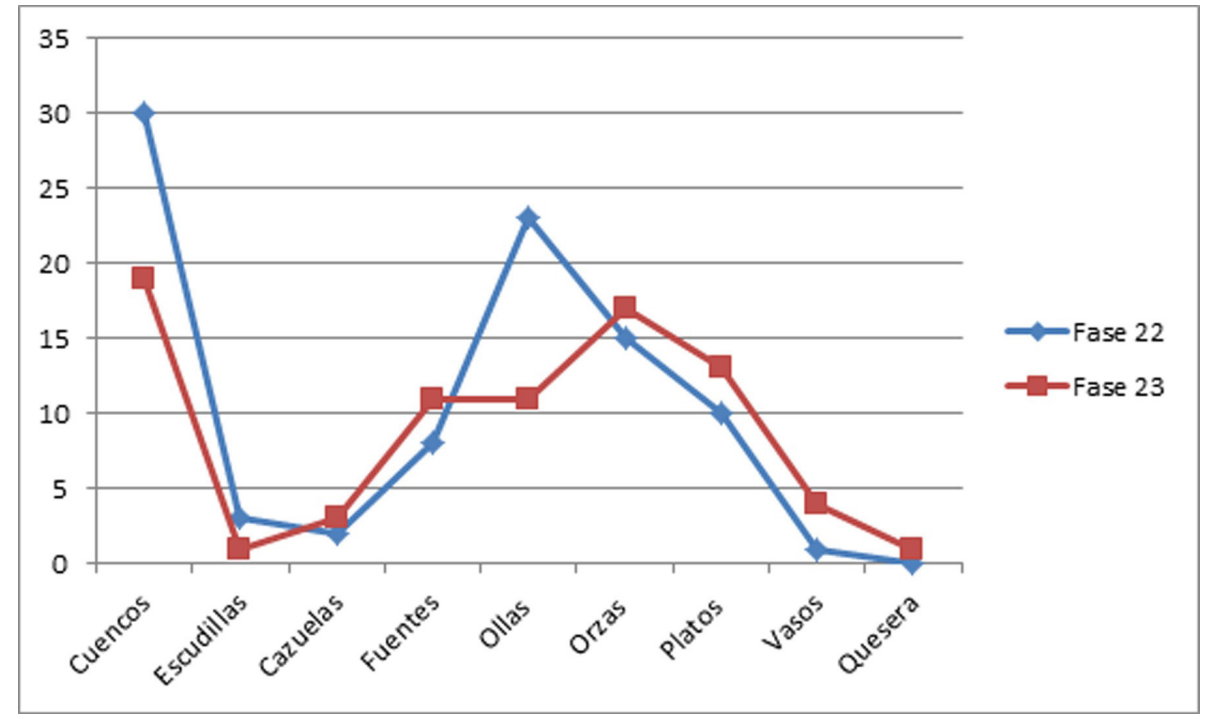

Figura 13. Gráfico con la tipología cerámica que conforma las dos fases cronoculturales del Cobre Reciente de Los Castillejos.

hubiera una sistematización de la tecnología de producción, pues no se puede establecer de forma clara que se utilizaran parámetros fijos para la realización de las vasijas. Pese a esto, aunque no podamos decir que existiera una fuerte homogeneización en la producción cerámica, $\mathrm{y}$, por tanto, nada sugiere la existencia de especialistas en esta actividad, sí se vislumbra una tradición en los modos de hacer cerámica ya que, a pesar de que no hay una fuerte estandarización técnica en el conjunto de las piezas según su forma (y presumiblemente su función), sí que podemos determinar un estilo en cuanto a formas (especialmente platos y fuentes) y la búsqueda de ciertas características técnicas en ciertas piezas (especialmente aquellas destinadas a ser expuestas al fuego o aquellas muy cuidadas). En relación con esto, hemos podido adscribir a ciertas actividades económicas unas formas concretas. También podemos referir una planificación y unas estrategias de elaboración claras, como hemos podido ver en el estudio tecnológico

\section{BIBLIOGRAFÍA}

Afonso, J.A.; Molina, F.; Cámara, J.A.; Moreno, M.; Ramos, R. y Rodríguez-Ariza, M. O. (1996): "Espacio y tiempo. La secuencia en Los Castillejos de Las Peñas de Los Gitanos (Montefrío, Granada)", I Congrés del Neolitic a la Península Ibérica. Formació e implantació de les comutitats agrícolas (Gavà-Bellaterra, 1995), Rubricatum 1:1. Actes. Vol. 1, Gavà 1996: 297-304.
Albero, D. (2011): Caracterización tecnológica, social y adaptación funcional de cerámicas prehistóricas en el oeste y sureste de Mallorca (1700-50 BC). Aproximación sincrónica y diacrónica a partir del estudio arqueométrico de pastas, Tesis Doctoral, Dpto. de Prehistoria y Arqueología de la Universidad de Granada.

Aranda, G. (2001): El análisis de la relación formacontenido de los conjuntos cerámicos del yacimiento arqueológico del Cerro de la Encina (Granada, España). BAR International Series 927. Oxford, Oxford University Press.

Arribas, A. y Molina F. (1977): "El poblado de Los Castillejos en Las Peñas de los Gitanos (Montefrío, Granada). Resultados de las campañas de 1971 y 1974", en XIV Congreso Nacional de Arqueología (Vitoria, 1975): 389-406. Zaragoza, Universidad de Zaragoza.

Arribas, A. y Molina F. (1979a): El poblado de "Los Castillejos" en Las Peñas de los Gitanos (Montefrío, Granada). Campaña de las excavaciones de 1971, Cuadernos de Prehistoria de la Universidad de Granada. Serie Monográfica 3. Granada, Editorial Universidad de Granada.

Arribas, A. y Molina F. (1979b): "Nuevas aportaciones al inicio de la metalurgia en la Península Ibérica. El poblado de Los Castillejos de Montefrío, (Granada)", in Proceedings of the fifth Atlantic Colloquium (Dublin 1979): 7-34. Dublín, Statoionery Office.

Arribas, A. y Molina F. (1987): "New Bell Beaker discoveries in the Southeast Iberian Peninsula", in Aldren, W. H. y Kennard,R.C. (eds.): Bell Beaker 
discoveries of the western Mediterranean. Definition, interpretation, theory and new site data The Oxford International Conference (Oxford, 1986): 129-146. Oxford, British Archaeological Reports. International Series 331 (I).

Arribas, A.; Molina F.; Sáez, L.; De la Torre, F.; Aguayo, P.; Bravo, A. y Suárez, Á. (1983): "Excavaciones en Los Millares (Santa Fe de Mondújar, Almería). Campañas de 1982 y 1983", Cuadernos de Prehistoria de la Universidad de Granada 8: 123-147.

Arribas, A.; Molina, F.; Carrión, F.; Contreras, F.; Martínez, G.; Ramos, A.; Sáez, L.; De la Torre, F.; Blanco, I. y Martínez J. (1987): "Informe preliminar de los resultados obtenidos durante la VI Campaña de excavaciones en el poblado de Los Millares (Santa Fe de Mondújar, Almería, 1985)", Anuario Arqueológico de Andalucía 1985 II: 245-262.

Blázquez, M. T. (2011): "Estudio tecnológico y estilístico de la cerámica decorada del Neolítico Antiguo Avanzado del yacimiento de "Los Castillejos" (Montefrío, Granada)", @rqueología y Territorio 8: $1-15$.

Calvo, M.; Fornés, J.; García, J.; Guerrero, V.; Juncosa, E.; Quintana, C. y Salvá, B. (2004): La cerámica prehistórica a mano: una propuesta para su estudio. Mallorca, El Tall Editorial.

Cámara, J. A.; Afonso, J.A. y Molina, F. (2016): "La ocupación de La Peña de los Gitanos (Montefrío, Granada) desde el Neolítico al mundo romano. Asentamiento y ritual funerario", en R.J. Pedregosa Megías, Arqueología e historia de un paisaje singular: Las Peñas de los Gitanos (Montefrío-Granada), pp. 18-121. Montefrío, Ayuntamiento de Montefrío.

Capel, J. (1985): Estudio mineralógico y geoquímico de cerámicas y sedimentos arqueológicos de algunos yacimientos de La Mancha, Tesis doctoral, Universidad de Granada, inédita.

Capel, J. y Delgado, R. (1978): “Aplicación de métodos ópticos al estudio de cerámicas arqueológicas". Cuadernos de Prehistoria de la Universidad de Granada 3: 343-356.

Capel, J.; Linares, J. y Huertas, F. (1979): "Métodos analíticos aplicados a cerámicas de la Edad del Bronce". Cuadernos de Prehistoria de la Universidad de Granada 4: 345-360.

Capel, J.; Molina, F.; Nájera, T.; Linares, J. y Huertas, F. (2001): "Aproximación al estudio de procedencia y tecnología de las cerámicas campaniformes del yacimiento de la Edad del Cobre de Los Millares". III Congreso Nacional de Arqueometría (Sevilla, 1999): 207-214. Sevilla, Universidad de Sevilla.
Chong, K. (2012): "Desgrasantes y cocción cerámica". Boletín de Arqueología Experimental 9: 94-102.

Contreras, F. (1986): Aplicación de métodos estadisticos y analíticos a los complejos cerámicos de la Cuesta del Negro (Purullena, Granada), Tesis doctoral, Universidad de Granada, inédita.

Cubas, M. (2013): La aparición de la tecnología cerámica en la región cantábrica. Oxford, BAR International Series 2566, Archeopress.

Cubas, M. y Ontañón, R. (2009): “The material evidence of the 'production sequence'. The case of the pottery ensemble of Los Gitanos cave (Castro Urdiales, Cantabria, Spain)". Journal of Iberian Archaeology 12: 7-22.

Cubas, M.; García-Heras, M.; Méndez, D. y De Pedro, I. (2012): "La tecnología cerámica de los niveles IV y III en el yacimiento de Kobaederra (Cortézubi, Bizkaia). Aprovisionamiento y modificación de las materias primas". Trabajos de Prehistoria 69 (No 1): 51-64. DOI: 10.3989/tp.2012.12079

Cuomo di Caprio, N. (2007): Ceramica in Archeologia 2. Antiche tecniche di lavorazione e moderni metodi di indagine. Roma, "L'erma" di Bretschneider.

Dias, M.I.; Prûdencio, M.I. y Valera, A.C. (2017): "Provenance and circulation of Bell Beakers from Western European societies of the 3rd millennium BC: The contribution of clays and pottery analyses". Applied Clay Science 146: 334-342.

Dorado, A. (2012): "El Bronce Final del SE Peninsular. Un análisis tecnológico de vasijas pertenecientes al corte 23 del Cerro de Los Infantes (Pinos-Puente, Granada)". @rqueología y Territorio 9: 95-116.

Duitama, L.; Espitia, C; Mojica, J.; Quintero, J. y Romero, F. (2004): “Composición mineralógica y química de las arcillas empleadas para cerámica roja en las zonas de Medellín, Itagüi y Amagá”. Revista de la Academia Colombiana de las Ciencias 28 (109): 555-563.

Esquivel, J. A.; Contreras, F.; Molina, F.; Capel, J. (1991): "Una aplicación de la Teoría de la Información al análisis de datos definidos mediante variables cualitativas multiestado: medidas de similaridad y análisis cluster". Complutum 1: 53-64.

Echallier, J. C. (1984): Éléments de Technologie Céramique et d'Analyse des Terres Cuites Archéologiques. Documents d'Archéologie Méridionale: Méthodes et Techniques 3, Lambesc.

Fernández Martín, S. (2011): Clasificación tipológica de la cerámica del yacimiento de la Edad del Bronce de la Motilla del Azuer (Ciudad Real, España). Oxford, BAR International Series 2377. 
Gámiz, J. (2011): “Aproximación al neolítico de la provincia de granada a través del estudio de la cerámica”.@rqueología y Territorio 8: 17-33.

Gámiz, J.; Dorado, A.; Cabadas, H. (2013): “Análisis de cerámica prehistórica con estereomicroscopía: una guía revisada sobre la descripción de las fases de producción". Cuadernos de Prehistoria y Arqueología de la Universidad de Granada 23: 365-385.

Gámiz, J. y Dorado, A. (e.p): "La transición del Neolítico Antiguo al Medio en Los Castillejos (Montefrío, Granada): aportaciones desde el estudio técnico estilístico de la cerámica", III Congreso de Prehistoria de Andalucía (Antequera 2014).

García Roselló, J. y Calvo, M. (2006): “Análisis de las evidencias macroscópicas de cocción en la cerámica prehistórica: una propuesta para su estudio". Mayurqa 31: 83-112.

García Roselló, J. y Calvo, M. (2013): Making Pots: el modelado de la cerámica a mano y su potencial interpretativo. BAR International Series 2540, Archaeopress, Oxford.

Gibson, A. y Woods, A. (1997): Prehistoric pottery for the archaeologist. Leicester, Leicester University Press.

IGME (1985-87): Mapa geológico de España a escala 1/50.000, HOJA 1008/990, 18-4/18/40. Montefrío y Alcalá la Real. Instituto Geominero de España, Madrid.

Gosselain, O.P. (1992): "Bonfire of the enquiries. Pottery firing temperatures in Archaeology: what for?". Journal of Archaeological Science 19: 243-259.

Kingery, W.D. (1997): "Opertional principles of ceramic kilns", The Prehistory \& History of Ceramic Kilns, en M.P. Rice y W.D. Kingery (coords.), Ceramics and Civilization Vol. VII, pp. 11-19. New Jersey, The American-Ceramic Society, Jonh Wiley \& Sons.

Lizcano, R. (1999): El Polideportivo de Martos (Jaén): un yacimiento neolítico del IV Milenio A.C. Córdoba, Obra Social y Cultural Cajasur.

Livingstone-Smith, A. (2001): "Bonfire II: The Return of Pottery Firing Temperatures". Journal of Archaeological Science 28: 991-1003.

Livingstone-Smith, A. (2007): Chaîne Opêratoire de la Poterie. Tervuren, Musêe Royal de l'Afrique Centrale.

Molina, F y Cámara, J.A. (2005): Los Millares. Sevilla, Dirección General de Bienes Culturales.

Molina, F y Cámara, J.A.; Dorado, A. y Villarroya, M. (2017a): "El fenómeno campaniforme en el Sudeste de la Península Ibérica: el caso del Cerro de la Virgen (Orce, Granada)", en V. Gonsalvez y C. Sousa (coords.) Sinos e taças. Gentes e artefactos.
Sobre a presença campaniforme em Portugal e Espanha. Estudos e Memórias. Lisboa, UNIARQCentro de Arqueologia da Universidade de Lisboa.

Molina, F y Cámara, J.A.; Afonso, J; A.; Martínez, G.; Gámiz, J.; Capel, J. (2017a). "Hiatus ina an archaeological multilevel site: Los Castillejos in Las Peñas de los Gitanos (Montefrío, Granada)", en M. C. A. Angelini (coord.), Limiti e oltre - Beyond limits. Studi in onore di Giovanni Leonardi, pp. 655664. Padova, University Press.

Moreira, J.M. (2003). "Las grandes unidades del relieve andaluz", en A. López (coord.), Geografía de Andalucía, pp. 81-117. Barcelona, Ariel Geografía.

Moreno, M. A. (1993): El Malagón: un asentamiento de la Edad del Cobre en el Altiplano de Cúllar-Chirivel, Tesis Doctoral, Universidad de Granada, inédita.

Nachasova, I. E; Burakov, K.S.; Molina, F. y Cámara, J.A. (2007): "Archaeomagnetic Study of ceramics from the Neolithic Los Castillejos Multilayer Monument (Montefrío, Spain)". Izvestiya. Physics of the Solid Earth 43(2): 170-176.

Navarro, J.V. (2008): “Aplicaciones de la Difracción de rayos X al estudio de los bienes culturales", en M. del Egido, S. Prous (coords.), La Ciencia y el Arte: ciencias experimentales y conservación del Patrimonio Histórico. Instituto del Patrimonio Histórico Español. Madrid, Ministerio de Cultura de España, 1: 134-139.

Navarrete, M. S.; Capel, J.; Linares, J.; Huertas, F.; Reyes, E. y Yáñez, J. (1991): Cerámicas neolíticas de la provincia de Granada, Monografía Arte y Arqueología. Granada, Universidad de Granada.

Odriozola, C.P. y Hurtado, V.M. (2007): "The manufacturing process of $3 \mathrm{rd}$ millennium $\mathrm{BC}$ bone based incrusted pottery decoration from the Middle Guadiana river basin (Badajoz, Spain)", Journal of Archaeological Science 34: 1794-1803.

Odriozola, C.P. (2012): Sistemas Técnicos de Producción Cerámica. Madrid, Editorial Académica Española.

Onieva, J.M. (1977): El municipio de Montefrío. Estudio Geográfico. Granada, Servicio de publicaciones de la Universidad de Granada.

Orton, C.; Tyers, P. y Vince, A. (1997): La cerámica en Arqueología. Barcelona, Crítica.

Pau, C. (2016): Los objetos de adorno en el Mediterráneo occidental en época campaniforme y su trascendencia social, Tesis Doctoral, Universidad de Granada, inédita.

Pellicer, M (1995): "Las culturas del neolítico-calcolítico en Andalucía Oriental", Espacio, Tiempo y Forma, Serie I, Prehistoria y Arqueología 8: 81-134. 
Pellicer, M. y Schüle, W. (1966): El Cerro de la Virgen. Orce (Granada) I. Madrid, Ministerio de Educación. Dirección General de Bellas Artes Servicio Nacional de Excavaciones Arqueológicas.

Ramos, U.; Afonso, J.A.; Cámara, J.A; Molina, F. y Moreno, M. (1997): “Trabajos de acondicionamiento y estudio científico en el yacimiento de Los Castillejos de las Peñas de los Gitanos (Montefrío, Granada)", Anuario Arqueológico de Andalucía/1993, vol III: 265-271.

Rice, P. M. (1987): Pottery analysis: A Sourcebook. Chicago, The University of Chicago Press.

Riquelme, J.A. (1998): Contribución al estudio arqueofaunístico durante el Neolítico y la Edad del Cobre en las Cordilleras Béticas: el yacimiento arqueológico de los Castillejos en las Peñas de los Gitanos, Montefrio (Granada), Tesis Doctoral, Universidad de Granada, inédita.
Rovira, N. (2007): Agricultura y gestión de los recursos vegetales en el sureste de la Península Ibérica durante la Prehistoria Reciente, Tesis Doctoral, Universitat Pompeu Fabra, Barcelona.

Ruíz Bustos, A. (1979): "Informe sobre la Geología de las Peñas de los Gitanos", en A. Arribas, F. Molina (eds.) El poblado de Los Castillejos en Las Peñas de los Gitanos, pp. 147-149. Granada, Editorial Universidad de Granada.

Sánchez Romero, M (1999): “Organización del espacio y producción de piedra tallada en Los Castillejos (Montefrío, Granada)", en II Congrés del Neolític a la Península Ibèrica (Alicante, 7-9 d'Abril 1999): 123-127. Alicante, Saguntum-PLAV Extra 2. Shepard, A.O., (1954): Ceramic for the archaeologist. Washington, Carnegie Institution of Washington.

Vico, L. (2016): “La cerámica del Cobre Reciente de Los Castillejos (Montefrío, Granada): estudio tipológico y decorativo". @rqueología y Territorio, 13: 1-14. 